\title{
PRETÉRITO IMPERFECTO Y CONDICIONAL CON DESINENCIA -IE- EN EL SIGLO XVI
}

\author{
F. GONZÁlez Ollé \\ Universidad de Navarra
}

1. La aparición y presencia del pretérito imperfecto de indicativo de la segunda y tercera conjugaciones (y del condicional de ellas y también de la primera) con formas en -ie-; su competencia con las formas originarias en -ia-; las causas de la amplia sustitución de estas últimas por aquéllas; su extensión y, en algunos textos, predominio; la posterior reposición de las desinencias primitivas, son varias cuestiones o, mejor, facetas y fases de un mismo y complejo problema evolutivo. Por cuanto alcanzo a percibir, cualquiera de estas incidencias ha suscitado más atención que la pervivencia del alomorfo -ie-. Posponiendo por ahora -en espera de mayor reflexión - ocuparme del núcleo profundo del problema - que aún no ha encontrado, a mi parecer, una solución satisfactoria de validez general ${ }^{1}$-, tampoco en este momento es mi intención abordar ninguno de los varios aspectos de él recién enunciados. Mi propósito presente apunta a otro aspecto, que, según acabo de decir, creo más desatendido: la perduración de las citadas formas en -ie-.

\footnotetext{
${ }^{1}$ La hipótesis que parece gozar de mayor predicamento, a juzgar por el número de menciones favorables, es la de Y. Malkiel, «Toward a Reconsideration of the Old Spanish Imperfect in -ia $\sim-i e ́ », H R$, XXVII, 1959, págs. 435-481. La discrepancia, implícita, pero más radical, respecto de su interpretación se encuentra en la obra de Alvar y Pottier que cito al final de esta nota. Me extraña no haber hallado nunca la mención, en los estudios sobre este problema, de otro trabajo del mismo autor, que, si bien mantiene la postura del anterior, sobre el que se basa, ofrece algunas precisiones valiosas de detalle. Me refiero a «Initial Points versus Initial Segments of Linguistic Trayectories", Proceedings of the Ninth International Congress of Linguists, La Haya, Mouton, 1964, págs. 402-405.

M. Alvar y B. Pottier, Morfología histórica del español, Madrid, Gredos, 1983, pág. 246, atribuyen el cambio a motivación teleológica: evitar la sinonimia entre $10^{\mathrm{a}}$ y $3 .^{\mathrm{a}}$ personas.
}

RFE, LXXX, 2000, $3 .^{\circ}-4 .^{\circ}$, págs. $341-377$ 
PERDURACIÓN DE -IE-

2. Las informaciones que he recogido sobre este punto y que ahora doy a conocer, justifican mi opinión. La extensa monografía de Malkiel recién citada acumula - como es práctica habitual en su autor- de modo probablemente exhaustivo todas las explicaciones precedentes a la suya sobre el problema planteado; acompaña su exposición con una imponente y admirable documentación medieval y dialectal; atiende con detalle numerosas cuestiones marginales en cuanto que admiten alguna vinculación con la principal, etc. Por el contrario, respecto a la persistencia de -ie- se limita a informar ${ }^{2}$ de que cambió «the tide after 1300 ».

Imhoff $^{3}$, en la más reciente monografía que conozco sobre la cuestión examinada, ha establecido unas útiles estadísticas sobre la distribución de las desinencias alomórficas del imperfecto en varias obras medievales. De ellas retengo que en la segunda mitad del siglo XIV la proporción de -ierespecto a -ia- se mueve entre el 32 y el $44 \%$; en la segunda mitad del siglo $\mathrm{XV}$ se ha reducido hasta situarse entre el 5 y el $15 \%$. «Not until 1492, as it were, did the Old Spanish -ie become a relic».

3. Expuestos tales datos cronológicos, la noticia proporcionada, hace unos cuantos años, por Moreno Fernández ${ }^{4}$, sobre la supervivencia de esta debilitada variante en el habla campesina actual de varias comarcas toledanas, ha de estimarse como un inesperado y valioso hallazgo. Para juzgar mejor aún sobre su alcance, completaré el escueto panorama temporal contenido en el apartado anterior con una sucinta mención de diversas indicaciones cronológicas, ofrecidas en los principales estudios, de carácter más general, atingentes a morfología histórica.

Domina en ellos la creencia compartida de que las formas en -ie- no llegaron a sobrepasar prácticamente la época medieval, a pesar de que algunos aducen testimonios y noticias antiguas sobre su supervivencia posterior.

\footnotetext{
${ }^{2}$ Y. Malkiel, «Toward a Reconsideration ... », pág. 477. En esta misma página reitera a propósito de la pérdida de -ie- "that there occurred, after 1300, a sharp reversal of the preceding trend».

${ }^{3}$ B. Imhoff, «On the Chronology and Recession of the Old Spanish -ie Imperfect», La Coronica, 26.2, 1998, págs. 243-255.

${ }^{4} \mathrm{~F}$. Moreno Fernández, «Imperfectos y condicionales en -ie, arcaísmo morfológico en Toledom, LEA $6,1984,183-211$. De los precisos datos, en especial sociolingǘsticos, del estudio, aquí sólo cabe retener la ausencia de la acentuación -ié-. Recientemente, el autor, "Castilla la Nueva", en M. Alvar (dir.), Manual de dialectología hispánica. El español de España, Barcelona, Ariel, 1996, 224, señala la presencia de -ie-, en pueblos de Guadalajara y Madrid; a la vez, apunta la posibilidad de que la desinencia sea debida a innovación.
} 
Tal continuidad cuenta con uno de sus más sólidos fundamentos en la observación censoria, exhumada por Menéndez Pidal ${ }^{5}$, del doctor López de Villalobos sobre el habla toledana, por comparación con la práctica castellana vieja, pues ésta, según aquel médico zamorano, no incurre en «decir hacién por hacia; ni comién por comían; y así en todos los verbos que son de esta conjugación» ${ }^{6}$. Menéndez Pidal se suma a la opinión de Villalobos $\mathrm{y}$, en su Manual de gramática histórica española, considera que «hacien era un defecto de pronunciación» y se adhiere a su juicio de que con él «los toledanos ensucian y ofuscan la polideza y claridad de la lengua castellana». Añade Menéndez Pidal que las formas con -ie- subsisten hasta época actual en aldeas de Astorga y «en gran parte de Asturias» ${ }^{7}$.

Sin menospreciar la relevancia cronológica de estos últimos datos, para la finalidad presente importa precisar y destacar que en torno a 1540 , desde Zamora, el erudito médico Villalobos atestiguaba que Toledo mantenía las formas con -ie-. La censura de Villalobos ha sido reiteradamente aireada, pero no he visto ninguna indicación sobre que mantuviese algún tipo de relación personal con el ámbito toledano, circunstancia favorable a la confirmación de su aserto. Por eso me parece oportuno añadir que tal relación existió, sin duda, a juzgar por el hecho de que en el Cancionero de Sebastián de Horozco se inserta un debate poético entre ambos.

4. Otro testimonio antiguo, no utilizado por Menéndez Pidal, aducido aun en estudios no específicos sobre la cuestión, procede de Correas ${ }^{8}$ :

${ }^{5}$ R. Menéndez Pidal, «El lenguaje del siglo XVI» [1933], en La lengua de Colón, Madrid, Espasa, $1947^{3}$, pág. 54 .

${ }^{6}$ La obra de donde procede la cita precedente no ha de datarse en 1515, como indica Menéndez Pidal, sino entre 1539 y 1542, según confio haber justificado en F. González Ollé, «Nuevos datos sobre la primacía lingüística toledana», RFE, LXVII, 1987, págs. 123-126.

${ }^{7} \mathrm{M}$. Taboada, «Lingüística hispánica renacentista: lenguas y dialectos en las gramáticas españolas de los siglos XVI y XVII (1492-1630)», Verba, XVI, 1989, págs. 77-95; pág. 94, consigna varias monografias que señalan su presencia actual en Asturias. Según J. Borrego Nieto, Norma y dialecto en el sayagués actual, Universidad de Salamanca, 1983, pág. 59, en Sayago "está languideciendo», si bien "aún puede encontrarse en el pueblo en el último grupo de edades, pero todos lo evitan en una situación de habla cuidada». Este mismo autor, «Leonés», en M. Alvar, Manual de dialectología hispánica. El español de España, Barcelona, Ariel, 1996, pág. 149, observa en las regiones de Omaña, Cepeda y Maragatería «la tendencia creciente a convertir las desinencias en -ia del imperfecto y el condicional en desinencias en -iá (con palatalización más o menos intensa de $a$, que puede desembocar en $e$ ): cumiá, tinié, cumiriè».

J. Lihani, El lenguaje de Lucas Fernández. Estudio del dialecto sayagués, Bogotá, Instituto Caro y Cuervo, 1973, pág. 252, señala un solo testimonio de imperfectos en -ie. A. Salvador Plans, La "fabla antigua» en los dramaturgos del Siglo de Oro, Cáceres, Universidad de Extremadura, 1992, no encuentra ningún caso.

${ }^{8}$ G. Correas, Arte de la lengua española castellana [1625], ed. de E. Alarcos García, Madrid, CSIC, 1954, pág. 269. Respeto la acentuación del editor. 
Por dialecto particular en Castilla la Nueva, Mancha i Estremadura i partes de Andaluzía mudan la $a$ en $e$ con el azento en esta forma: ie, ies, ie, iemos, iedes o ieis, ien. I se usa mucho entre no letrados, como avié, aviés, aviémos, aviedes, avién, dizié, diziés, dizié, quirié, quiriés, quirié, etc., por avia, avias, dezia, dezias, queria, querias, etc. Mas no está rrezibido entre los elegantes, aunque pudiere pasar por dialecto de tan nobles provinzias.

Pero, aun reconociendo su antigüedad - prosigue Correas-, la unidad idiomática existente en España ya no permite «más que una propiedad i puridad castellana, sin mezcla, ni bolver a lo viexo».

Como López de Villalobos, Correas establece una delimitación geográfica del fenómeno, con el dato interesante de que en ella cabe insertar la marcada por aquél. También establece otra restricción, ésta de naturaleza social, al considerarlo ajeno a los elegantes. Pero, aun con tan sensibles limitaciones, la atestiguación de las formas en -ie- queda prolongada hasta bien entrado el siglo XVII. Lo cual implica que, aproximadamente, sobrepasa en más de 80 años la información suministrada por Villalobos.

5. Vuelvo a las obras de carácter general.

En palabras de García de Diego ": «quedó -ié a principios del XVI como un vulgarismo del habla de Toledo».

Según Alvar y Pottier ${ }^{10}$, "en el siglo XIV, las formas en ie comenzaron a «perder terreno», aunque duraran en algún texto del siglo XVI».

Para Penny ${ }^{11}$, «hacia el siglo XV volvieron a imponerse las formas en -ia-».

En opinión de Lloyd ${ }^{12}$, «después de 1300 el imperfecto en -ie empezó a retroceder, hasta que, al fin, quedó relegado a un pequeño número de dialectos sociales y regionales. En los primeros años del siglo XVI, era ya un residuo del pasado» ${ }^{13}$.

6. Se puede observar una secuencia más minuciosa de la evolución del imperfecto, trazada de modo discontinuo por la naturaleza de la exposición, en Lapesa ${ }^{14}$. Éstas son, resumida su presentación, las fases que señala: vacilación temprana -ia- -ie-; imperfecto y condicional en -ie-, de presencia frecuente en el Arcipreste de Hita, pero, en general, abandonados en su época, aunque después todavía se registran bastantes casos de -ie-; en la primera mi-

\footnotetext{
${ }^{9}$ V. García de Diego, Gramática histórica española, Madrid, Gredos, $1970^{3}$, pág. 229.

${ }^{10}$ Alvar y Pottier, Morfología ..., pág. 242.

11 R. Penny, Gramática histórica del español, Barcelona, Ariel, 1993, pág. 189.

12 P. M. Lloyd, Del latin al español, I, Madrid, Gredos, 1993, pág. 578.

13 Esta afirmación parece basarse en el testimonio, que cita, de Villalobos; lo data, según ha venido siendo general, en 1515. Pero, como antes dije, ha de retrasarse varios decenios.

${ }^{14}$ R. Lapesa, Historia de la lengua española, Madrid, Gredos, $1981^{9}$, pássim.
} 
tad del siglo XV son escasas las formas verbales serién, podrié; entre otros arcaísmos, de variado orden, menciona sabién en los escritos de Santa Teresa.

7. El punto sobre el que reina mayor unanimidad entre los autores aducidos - las informaciones precedentes lo dejan claro- es precisamente el de la práctica extinción del alomorfo -ie- a comienzos del siglo XVI, sin haber conocido la verdadera data de la noticia suministrada por Villalobos $(\S 3)$ y dejando un tanto marginada la posterior noticia de Correas $(\S 4)$.

\section{SANTA TERESA}

8. Para el citado siglo XVI, al testimonio teresiano aducido por Lapesa, puedo añadir otros ${ }^{15}$ de la misma autora en su Libro de la vida. Las circunstancias que acompañan su presencia merecen un particular comentario.

Aunque apenas pueda pasar de constituir un hecho anecdótico, apuntaré que Santa Teresa terminó la primera relación, hoy perdida, de su mencionada autobiografía el año 1562, precisamente en Toledo. Sin embargo, el dato consignado se encuentra estrechamente unido con otros ${ }^{16}$ a los que cabe conferir mayor alcance sobre la cuestión aquí examinada.

Según refiere la propia Santa, en dicho año, por obediencia, se trasladó a Toledo (ciudad en la que luego pasó varias estancias de menor duración), donde residió más de seis meses, alojada en el palacio de una de las principales señoras del Reino. Allí redactó, también por obediencia (cf. infra), la noticia, no conservada, de su vida, en un ambiente cortesano, sujeta a una obligada vida social, que «harto» disgustaba a su deseo de recogimiento monástico. Probable parece que, en virtud de estas circunstancias y por el trato con «aquellas tan señoras» asiduas concurrentes al palacio - cuyas conversaciones sin duda no se caracterizarían precisamente por el «estilo de ermitaños»-, alcanzase Santa Teresa a escuchar de modo cotidiano - no resultaría prudente suponer que por primera vez ni que entonces sufriese su contaminación- las formas verbales en -ie-, a juzgar por lo que más adelante atestiguaré sobre su vigencia en el habla de los toledanos.

Como otra vía para esta posible influencia, durante los mismos meses, cabe señalar el encuentro casual con el dominico P. García de Toledo, toledano, «con quien muchos años avía tratado algunas veces» sus asuntos es-

\footnotetext{
${ }^{15}$ Suelen consignarlos, no todas, las ediciones solventes, en el cuerpo de la obra o en nota, según los criterios editoriales, aunque no siempre acierten en su interpretación.

${ }^{16}$ Los extraigo, simplificados y articulados para el propósito perseguido, de la misma $\mathrm{Vi}$ da teresiana.
} 
pirituales. Lo halló «más avisado que nunca», por lo cual, de nuevo, acudió a sus consejos. De su ascendiente sobre la santa proporciona prueba inmejorable que él fue quien le pidió poner por escrito su vida, como ella ejecutó pronto, según antes he consignado. $\mathrm{Y}$, aun poco tiempo después de que dejase Toledo, le indicó que añadiese algunos acontecimientos recientes.

Fue asimismo en Toledo, lugar, como antes indiqué, de otras estancias posteriores, donde redactó dos de sus otras obras: la segunda versión, muy modificada, de Camino de perfección, durante varios meses pasados en dicha ciudad el año 1569, y Visita de Descalzas, en agosto de 1576.

Pero todavía cabe sacar algunas otras consecuencias, de interés para la finalidad presente, a partir de la suerte corrida por el Libro de la vida teresiano. La versión definitiva del texto autobiográfico, cuyo autógrafo se conserva, elaborada a la vista de la primera, no se produjo hasta los años 15641565. Durante ellos, su autora la revisó a fondo y dividió en capítulos.

Bajo la nueva redacción, corrieron múltiples copias manuscritas de ella, hasta que en 1588 (Salamanca, Guillermo Foquel; los preliminares, septiembre de 1587), por encargo real, Fray Luis de León preparó su publicación, junto con otras obras de la santa (a quien no había conocido). Más interés encierra desvelar que, si bien el editor asegura haber respetado los originales teresianos, sin introducir modificaciones «ni en palabra ni en cosas», limitándose a ordenar algunas distorsiones sintácticas ${ }^{17}$, de hecho su enmienda debió de extenderse más allá de la sintaxis y del léxico ${ }^{18}$, pues en el manuscrito ${ }^{19}$ se hallan las formas desembolviemonos (ii $r$ ), entendien (lxix $v$ ) y açie (ci v), cuyo común segmento -ie- sustituye por -ia- en los tres casos (además de introducir otros cambios, aquí secundarios, como eliminar el pronombre enclítico en la primera palabra citada y trascribir la tercera por hazia).

\footnotetext{
${ }^{17}$ En el envio a las religiosas carmelitas, asevera Fray Luis de León, a propósito de los libros teresianos, «que ha trabajado [...] en cotejarlos con los originales mismos que estuvieron en mi poder muchos días, y en reduzirlos a su propria pureza en la misma manera que los dexó escritos de su mano la Madre, sin mudarlos ni en palabras ni en cosas, de que se avían apartado mucho los traslados que andavan [...]. Fue atrevimiento grandísimo y error muy feo querer emendar las palabras, porque si entendieran bien castellano, vieran que el de la Madre es la misma elegancia». No deja, sin embargo, de observar que la santa «en algunas partes de lo que escrive, antes que acabe la razón que comiença, la mezcla con otras razones, y rompe el hilo començado muchas veces con cosas que inxiere, pero procede tan diestramente que esse mismo vicio le acarrea hermosura y es el refrán del lunar. Ansí que yo los he restituido a su primera pureza».

${ }_{18}$ Acerca de esta cuestión, of. M. L. García-Macho y J. A. Pascual, "Sobre la lengua de Santa Teresa: el valor de sus elecciones gráficas evitadas por Fray Luis», Mélanges de la $\mathrm{Ca}$ sa de Velázquez, 1990, 26, págs. 129-140. Los mismos autores acaban de retomarla en «De nuevo sobre los usos gráficos en la edición que Fray Luis de León hizo del Camino de Perfección de Santa Teresa de Jesús», Lengua y discurso. Estudios dedicados al Profesor Vidal Lamiquiz, Madrid, Arco/Libros, 2000, págs. 367-375.

${ }^{19}$ Lo leo por el facsímil, acompañado de trascripción paleográfica, de T. Álvarez, Madrid, Patrimonio Nacional, 1999.
} 
De esta última interesa copiar su contexto autógrafo, como prueba de la copresencia alomórfica: Antes pareçia açie poco; enseguida, movia. Apenas habrá de concluirse que para Fray Luis (recuérdese que su lugar de nacimiento queda en el área de -ie- denunciada por Correas) no eran admisibles las formas con -ie-, nativas (recuérdese asimismo que Castilla la Vieja pertenecía a dicha área) en Santa Teresa o adquiridas por contaminación toledana. Ésta es la enseñanza que he pretendido sacar del proceso de edición.

\section{ESCRITORES VARIOS}

9. Como en el caso recién examinado, también en diversos estudios ajenos a la finalidad presente, se encuentran señalados otros testimonios contemporáneos, dispersos, de -ie-. Doy cuenta de los que conozco, junto con los procedentes de mis lecturas personales previas.

El talabricense Fernando Alonso de Herrera, nacido hacia 1460, desempeñó las cátedras de Gramática y de Retórica en la Universidad de Alcalá entre 1509 y 1512; la de Retórica en Salamanca, entre 1517 y, al menos, 1526. Fue humanista de renombre entre ilustres contemporáneos españoles y extranjeros con quienes mantuvo trato y correspondencia, comentarista de las Elegantiae de Valla, autor de varios libros de las citadas materias. Publicó también (Salamanca, 1517) el diálogo Disputatio adversus Aristotelem Aristotelicosque sequaces, libro ahora objeto de mi atención, una obra bilingüe en la cual aparecen enfrentados el texto latino con el español ${ }^{20}$. En este tratadito filosófico he encontrado las siguientes cinco formas verbales: querrie, aurie, querriedes, auie, bolarie. Su inventario apenas es superado por las correspondientes formas en -ia-, que aparecen en seis ocasiones.

El testimonio de Alonso de Herrera se alza como primera muestra de la vigencia otorgada a las formas con -ie- entre la clase ilustrada toledana durante el primer tercio del siglo XVI.

10. La Farsa del Santisimo Sacramento ${ }^{21}$, anónima, fue escrita en 1521 , durante unas vacaciones escolares, por un autor que, en una extensa y correcta dedicatoria latina, se declara joven y estudiante. Salvo $\mathrm{Fe}$, los

\footnotetext{
20 Todos estos datos y otros muchos que avalan su condición de hombre muy docto -aspecto que me interesa realzar-, proceden de A. Bonilla San Martín, "Un antiaristotélico del Renacimiento: Hernando Alonso de Herrera ... ". RH, L, 1920, págs. 61-196; el texto del diálogo, págs. 97-183. El razonamiento de Bonilla para dar la fecha de nacimiento permite retrasarla algunos años, a juzgar por varios acontecimientos de su vida; pero ésta es cuestión secundaria aquí.

${ }^{21}$ F. González Ollé, «La Farsa del Santisimo Sacramento, anónima, y su significación en

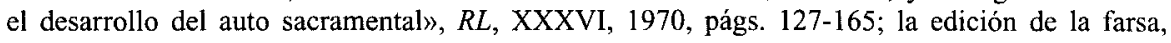
págs. $142-62$.
} 
restantes personajes son pastores y en sus intervenciones se encuentran todos los rasgos característicos del sayagués. Algunos cultismos sintácticos y léxicos, las reminiscencias de textos escriturarios e himnos eclesiásticos, etc., ratifican la apuntada condición culta del autor, cuya procedencia regional permanece sin patentizar.

Pues bien, en esta breve obra dramática se registra la presencia, minoritaria (el polimorfismo afecta también a otras muchas palabras ajenas al caso presente), de diversos lexemas verbales en -ie-: vinie, avien, espantariés (acentuación garantizada por la rima con es, pero espantarias, en rima con armonías), solie. Salvo en el caso comentado, en los restantes se puede dudar de la acentuación, dada la inseguridad del metro (la inflexión inclina obviamente a vinié en el primero citado), pero no cabe achacar la terminación -ie- a condicionamiento de la rima, pues su presencia se revela espontánea en interior de verso.

11. En un breve repertorio de peculiaridades verbales históricas, Cirot ${ }^{22}$ incluye auie y acabariemos, tomados de Juan de Valdés, Diálogo de la lengua, con referencia a la edición de E. Boehmer (página 468). Esta edición (que no he podido ver ${ }^{23}$; las indicaciones sobre ella proceden todas de Cirot) fue publicada en Romanische Studien, 1985, 6, págs. 339-508; ahora bien, según la descripción bibliográfica, el texto, atenido al manuscrito de Madrid, alcanza hasta la página 420 , a la que siguen extensas observaciones ecdóticas, gramaticales, léxicas, etc. Luego cabe conjeturar que las aducidas formas verbales que «Boehmer a relevées dans le Diálogo de la lengua», necesariamente habrán de ser variantes respecto de los manuscritos de Londres y de El Escorial. Acerca del manuscrito madrileño (al que se atienen también las ediciones de Lapesa - selectiva-, Barbolani y Lope Blanch) no suele decirse que a la Biblioteca Nacional de Madrid llegó procedente de la Catedral de Toledo y que antes había pertenecido al humanista toledano Alvar Gómez de Castro (a cuya mano atribuye Boehmer, quien sí señala el origen toledano del manuscrito, algunas perícopas). $\mathrm{Y}$ no se olvide que el conquense Valdés se consideraba, con razón, «hombre criado en el Reino de Toledo».

Cirot consigna asimismo desenvolviemos, en Santa Teresa, Vida (ya citado aquí), y habien, en López de Gómara, sin indicar de qué ediciones se vale.

${ }^{22}$ G. Cirot, «Sur quelques archaïsmes de la conjugaison espagnole», BH, XIII, 1911, págs. $82-90$.

23 J. Fernández Montesinos declara en la suya, Madrid, 1926, que es dificil encontrarla aun en Alemania. «Nos ajustamos a la edición de J. Boehmer», declara J. Moreno Villa en la publicada por él en Madrid, Calleja, 1919. Sin embargo, su texto no presenta ningún testimonio de auie ni acabariemos (en su lugar, acabariamos). 
12. En La lozana andaluza (1528), Frago ${ }^{24}$ ha señalado «el mantenimiento de la desinencia -ie del imperfecto de indicativo en varias ocasiones». Recuérdese que Delicado era originario de Andalucía, otra de las áreas de dicha variante, según Correas.

La recientemente descubierta primera edición del Lazarillo (Medina del Campo, 1554), presenta, según Cañas ${ }^{25}$, cuatro formas verbales en -ie-, frente a -ia- en las otras tres ediciones del mismo año: parien, parecien, valdrien, hallarie. A los partidarios de un origen toledano de la novelita, quizá les proporcionaría alguna utilidad reparar en la inesperada presencia de estas variantes morfológicas.

13. Cuando preparé la edición de las obras dramáticas del toledano Sebastián de Horozco ${ }^{26}$ (la primera representada en $1548^{27}$; otra en 1550; se ignora la data de las restantes), por 38 incidencias de -ia-encontré 18 de -ié(serié, pidié, avién, estarién, etc.), más una de -ie- (harie), según permiten deducir el metro y la rima; la proporción viene a resultar, pues, de $2 / 1$.

Se reparten entre todas las personas verbales, salvo la segunda de singular y la primera de plural, pero sépase que éstas tampoco se documentan con - ía-. Dada su escasa presencia histórica, consigno las dos manifestaciones de -ié- en la 1. a persona de singular, podrié (Entremés, v. 195) y avié (ib., v. 223). En las formas paroxítonas de la 2. ${ }^{a}$ de plural, la lengua de Horozco apenas presenta casos de conservación de la $-d$ - desinencial, sólo observo 6 , pero llamo la atención sobre ellos porque 4 corresponden a la terminación $-i e ́$ - Parecen justificarse así mutuamente ambos rasgos como supervivencia de una fase por lo general superada en la lengua contemporánea.

Tales formas con -ie- predominan en boca de villanos, pero conviene advertir que a esta clase social pertenece la mayoría de los personajes creados por Horozco, distribución que descarta cualquier vinculación diastrática. En efecto, el mayor número de las registradas corresponde al Entremés, la pieza en que más presencia tienen los personajes de ruda condición. Ahora bien, se hallan asimismo en parlamentos de otros revestidos de superior estima como Jesucristo y Litigante. Además, la frecuencia proporcional de su

24 J. A. Frago Gracia, «Actitud del historiador de la lengua ante los textos escritos», Boletín de la Academia Puertorriqueña de la Lengua Española, 1, 1992, págs. 33-69; pág. 64.

${ }^{25}$ J. Cañas Murillo, "Un Lazarillo de Medina del Campo: peculiaridades y variantes de una edición desconocida de 1554», $A E F, 19,1996$, págs. 90-134; pág. 130.

${ }^{26}$ S. de Horozco, Representaciones, ed., intr. y notas de F. González Ollé, Madrid, Castalia, 1979. Están contenidas en su Cancionero, que Gallardo creía autógrafo y así se ha sostenido después alguna vez, pero hay indicios más concluyentes, a mi entender, de que es un probable apógrafo, copiado hacia 1580 . Volveré más adelante a examinar otras obras de este autor.

${ }^{27}$ Corrijase así la fecha de 1584 , que figura en mi edición recién citada, paciente de un desafortunado proceso editorial. 
aparición no resulta suficientemente alta como para suponer que con ellas se intenta caracterizar idiomáticamente a aquel estamento, al que sí se adjudican algunos rasgos propios del sayagués.

Todavía una última observación, más decisiva que las anteriores a efectos de morfología histórica. En posición final de verso aparecen 7 manifestaciones de -ié-, con esta acentuación, que pueden ser atribuidas a conveniencia o necesidad de la rima. Así se revela indudablemente en Historia evangélica, v. 547 , donde figura el imperfecto vié, en consonante con $f e$, tiempo verbal que en el verso siguiente se repite mediante el alomorfo veía, en rima con Mexía. De las restantes 12 incidencias, en interior de palabra, 11 presentan también el esquema acentual -ié-; solamente una, harie, en Entremés, v. 69, difiere, por exigencia del cómputo silábico. Luego habrá de deducirse que esta variante, a diferencia de las demás, carece de cualquier sospecha de condicionamiento formal, pues a tal efecto equivale a -ia-, cuyo hiato la invalidaba, por razones métricas, para las demás apariciones. En todas las otras, insisto, cabría aducir motivos para suponer que la conveniencia hubiera forzado la elección de la forma menos usual, pero igualmente dentro de la tradición castellana. Más adelante ( $\S \S 31-34)$ volveré sobre otros textos de Horozco y confirmaré esta impresión.

Vale concluir que, a mediados del siglo XVI, los espectadores teatrales toledanos admitían sin extrañeza el alomorfismo del imperfecto y del condicional. Tal actitud no puede sorprender hoy, si esa misma alternativa era compartida en obras filosóficas como la de Herrera y en otras que luego examinaré.

14. Ya entrado el siglo XVII, en el Cancionero para cantar la noche de Navidad y las fiestas de Pascua, fecho por Francisco de Ocaña (Alcalá, Juan Gracián, 1603) ${ }^{28}$, la poesía Anda acá, amigo Bras atestigua tañien en rima con bien. En $O$, quien con vos encontrara, el trístico inicial y las siete septillas siguientes llevan Bethlen como palabra final del último verso, en rima con sus respectivos penúltimos, obtenida mediante bien, bien, desden, ponien, quien, bien, hazien, ofrezien. Figuran, por tanto, tres imperfectos en -ién. En toda la composición sólo hay una incidencia más de este tiempo verbal, ofrecia, pero admite la duda, como las otras en -ién, sobre su espontaneidad, pues también está situado en posición de rima, con agonia.

La misma circunstancia concurre en la mayoría de los imperfectos y condicionales con terminación -ia(s) que documenta este Cancionero: se presentan en posición de rima con sustantivos o adjetivos en -ia(s) o riman entre sí (reya, hazia, dezia). Ajenos a este tipo de condicionamiento o a

${ }^{28} \mathrm{He}$ manejado la edición de A. Pérez Gómez, Valencia, La fonte que mana y corre, 1957. 
cualquier otro (el silábico no cuenta, dada la fluctuación métrica imperante) sólo encuentro seis formas verbales en -ia. Estos datos se muestran suficientes para asegurar que las formas en -ie- responden a una oportunidad métrica, pero no suponen un recurso artificioso, sino justificado, en cuanto arcaísmo vigente, que cabría equiparar con los casos de -e paragógica presentes en el mismo Cancionero.

Las poesías examinadas no tienen por qué ser necesariamente anteriores o muy anteriores a la fecha consignada, pues, al igual que suele constar en casi todas las del volumen, se indica el tono correspondiente a canciones, de reconocida popularidad, con que han de ser cantadas. Del autor, nada se sabe; pero la configuración geográfica de su nombre evidencia, una vez más, la relación con Toledo.

\section{TOLEDANISMO}

15. Los datos aportados hasta aquí, procedentes, según advertí, de mis lecturas ocasionales, bien sobre los propios textos, bien sobre estudios marginales a la cuestión, facultan a creer que una búsqueda específica proporcionaría nuevos testimonios. En cualquier caso, estimo que la dispersión y variedad de los aducidos resultan suficientes para afirmar ya que las formas verbales en -ie- conocían más extensión y vitalidad de la que hasta ahora se les otorgaba.

El otro dato que se desprende del repertorio establecido - apenas debo declararlo a estas alturas- - es su preferente adscripción a autores toledanos.

Esta condición de carácter local me ha decidido a interesarme por las poesías de Rodrigo de Cota, dada su naturaleza toledana, aunque por razones cronológicas no correspondería aquí ocuparse de su lengua. Pero quiero pensar que no ha sido en vano.

El Diálogo entre el Amor y un Viejo, según la edición de Foulché-Delbosc ${ }^{29}$, presenta las formas (sin tilde acentual, de acuerdo con el criterio adoptado para todo el volumen) solies (v. 13), dexarias (v. 98) y auia (v. 543). La correcta medida de los respectivos octosílabos en que se encuentran, exige las acentuaciones solié, dexariás y auía. En la edición de Aragone ${ }^{30}$ (que sigue la de 1511) se encuentran solies, dexarias y havia, con estas marcas gráficas acentuales, pero las dos primeras no son aceptables, por la razón indicada. En la edición de Medina del Campo, 1569, solies ha sido

${ }^{29}$ R. Foulché-Delbosc, Cancionero castellano del siglo XV, Madrid, Bailly-Baillière, 1915 , II, págs. 580-587.

30 Diálogo entre el Amor y un Viejo, ed. de E. Aragone, Florencia, Le Monnier, 1961. 
remplazado por solia, que, leído solía, regulariza el metro y evita una terminación que había de sentirse anómala; dexarias, por dexauas, si bien de modo forzado, salva asimismo el inconveniente, por inusual, de dexariás. Como puede juzgarse, los cambios introducidos son sintácticamente considerables, de modo que también así habían de estimarse las anomalías.

En un epitalamio, sátira antijudaica, plagado de hebraísmos y de alusiones crípticas que hacen el texto de difícil comprensión, la edición de Foulché-Delbosc ${ }^{31}$ presenta faria (v. 21a), en rima con falsia, y además tomaria (v. 22d), que ha de leerse tomaria. Una versión más reducida, pero con estrofas nuevas y con multitud de discrepancias de todo orden respecto de la anterior, editada por Azáceta ${ }^{32}$, no contiene el primero de los condicionales antes citados, pero sí el último, tomarie, que exige la lectura tomarié $(4 h)$. Esta nueva versión de la poesía incluye el imperfecto pidie $(8 h)$, que ha de leerse pidié.

Para fundamentar con mayor solidez la adscripción toledana de las formas en -ie- durante el siglo XVI, he efectuado un examen sistemático de las obras de dos fecundos autores toledanos del siglo XVI, en buena parte de su vida contemporáneos y conciudadanos, pero con personalidades contrapuestas, de muy distinto nivel cultural y talante literario, cultivadores de géneros también muy diversos. Me estoy refiriendo a Alejo Venegas y a Sebastián de Horozco (este último ya aducido a propósito de una parte de sus obras, las dramáticas). Continuaré luego con dos obras contemporáneas, radicalmente dispares por su espíritu de las anteriores, las poesías de Garcilaso y la traducción de la Arcadia. Mediante esta diversidad textual, el análisis permite alcanzar una variada muestra de registros lingüísticos.

\section{ALEJO VENEGAS}

16. Según ha precisado recientemente Adeva Martín ${ }^{33}$, Alejo Venegas, de familia noble y sin recursos, hijo de padres toledanos y cristianos viejos, na-

\footnotetext{
${ }^{31}$ Foulché, Cancionero ..., págs. 588-591.

32 J. M. Azáceta, «El "Pequeño Cancionero"», EDMP, Madrid, CSIC, 1957, VII, págs. 83112. Así se denomina una recopilación de poesías de diversos autores de los siglos XV y XVI. La letra del manuscrito se data a finales del siglo xvi. En el epitalamio aparecen también las insólitas formas verbales de tercera persona sali, fazi y venin, que funcionalmente admiten ser interpretadas como imperfectos. No encuentro argumentos sólidos para decidir cuál haya sido, entre los varios posibles, su previo estadio morfológico. Desde una consideración fonética, está claro que -ie- ofrece las mayores posibilidades, pero la presencia de las variantes acentuales tomarié, pidié (cf. supra) debilita notablemente tal atribución.

${ }^{33}$ I. Adeva Martín, El Maestro Alejo Venegas de Busto. Su vida y sus obras, Toledo, IPIET, 1987. Esta monografia, de donde extraigo los datos biográficos de Venegas, cuenta con una amplia colección de documentos, incluidos y revisados los que ya habian sido publicados.
} 
ció el año 1498, en Camarena, lugar a pocos kilómetros de Toledo. En esta ciudad residió desde su primera infancia, hizo sus estudios iniciales, contrajo matrimonio (su mujer procedía de Illescas), se graduó en Artes Liberales (bachiller, 1521; maestro, 1526) en la Universidad, fue profesor en el Estudio de Gramática, desde antes de 1531 hasta 1544, año en que, por su prestigio, fue llamado para igual cargo en el de Madrid, a donde se trasladó. Allí, en el desempeño de la docencia, disfrutó de creciente auditorio y éxito, hasta el punto de que el Ayuntamiento de la villa hubo de aumentar el número de bancos para los estudiantes y, para el maestro, su salario, a fin de retenerlo. Ejerció el «oficio» (así lo denomina él) de «visitar los libros que vienen a esta ciudad de Toledo» (Diferencias, ii $r$; en otros momentos, «visitador de libros» y «visitar las librerías públicas y particulares»). Presentó su candidatura a la cátedra salmantina de prima de Gramática, pretensión de la que no se conoce ninguna otra noticia. Cesó en Madrid en 1560, volvió a Toledo (ciudad con la que nunca había dejado de tener variadas relaciones) y murió allí en 1562.

El nombre de Venegas aparece en prólogos, aprobaciones, censuras, etc., de numerosos libros, entre ellos algunos muy reputados, como las Obras (1546), de Cervantes de Salazar, su discípulo predilecto; Los coloquios satíricos (1553), de Torquemada; Los Triunfos (1554), de Petrarca; Aritmética (1554), de Pérez de Moya; Grammatices Latinae Institutiones (1562), del Brocense ${ }^{34}$, etc.

Es notable la diversidad de asuntos abordados por Venegas en sus propias obras, varias de las cuales fueron objeto de numerosas reediciones. Entre ellas sobresalen:

Tractado de Orthographia y accentos en las tres lenguas principales ... (Toledo, Lázaro Salvago, 1531). Aunque parece ser que no llegó a reeditar$\mathrm{se}^{35}$, obtuvo gran difusión, pues en la segunda mitad del siglo fue plagiada y muy citada ${ }^{36}$. Resultan muchas - quizá excesivas- las autoridades aducidas (en especial, Nebrija), pero también adopta puntos de vista personales. Es el primer libro español que aborda conjuntamente el estudio de hebreo, griego y latín.

Agonía del tránsito de la muerte ... (Toledo, Juan de Ayala, 1537). Su mejor obra, que alcanzó una pronta y enorme fama: en 1583 llegaba a la $11 .^{a}$ edición; desde entonces siguió imprimiéndose de modo muy espaciado. Es un tratado de ars moriendi, sustentado sobre la personal experiencia de su autor en la atención a un amigo durante su enfermedad y fallecimiento.

\footnotetext{
34 Por encargo del Consejo Real. Observa Venegas que «en muchas cosas se aparta de la común opinión de los gramáticos de España», pero «funda su intención con razones i autoridades de excelentes gramáticos antiguos y modernos». Concluye con un parecer favorable.

${ }^{35}$ Hay edición facsimilar, con estudio de L. Nieto, Madrid, Arco/Libros, 1986.

36 Adeva, El Maestro ..., págs. 210-211.
} 
A partir de la $3 .^{a}$ edición (Toledo, Juan de Ayala, 1543) incluye una Breve declaración de las sentencias y vocablos obscuros ..., que se publicó también independientemente; contiene 231 lemas. Esta obrita, de 56 hojas, es más enciclopédica que lexicográfica.

Primera parte de las diferencias de libros que hay en el Universo (Toledo, Juan de Ayala, 1540). La 5. a y última edición es de 1583. Esta obra, cuya publicación quedó incompleta (hay indicios de que llegó a terminarla), responde a un vasto proyecto de instrucción para los iletrados, con una finalidad teológica y moral. Su título ha desorientado a veces, pues se ha querido ver en ella una recopilación bibliográfica. Venegas pretende que quienes no comprenden latín, alcancen un conocimiento sólido del mundo físico, el racional y el sobrenatural, para lo cual despliega una enorme erudición («ha leído gran número de autores de diversas facultades», aseguran los preliminares) en todas las ramas del saber. En la obra veneguiana, libro ha de entenderse metafóricamente: el libro original es una exposición sobre la existencia de Dios; el natural, sobre Cosmología; el racional, sobre Antropología y Sociología; el revelado, sobre la Sagrada Escritura y la Iglesia.

Al margen de los elogios más o menos convencionales en los preliminares de sus obras, dispensados por ilustres amigos y humanistas, Venegas los recibió muy encendidos de García Matamoros, Ginés de Sepúlveda, Nicolás Antonio, etc.

17. Con todas las precedentes informaciones, que a primera vista pueden parecer de inoportuna extensión, he pretendido dejar bien patente, para una interpretación posterior, la amplia formación cultural que Venegas exhibe, en alto nivel intelectual, así como su estrecha vinculación con Toledo. Con todo, quiero seguir insistiendo en ambos aspectos, que voy a observar a continuación, de modo directo, en sus obras.

Por la naturaleza misma de éstas, se comprende enseguida que Venegas maneje una gran riqueza de vocabulario. Sus obras están empedradas de un considerable número -al menos en parte, inevitable por necesidades denominativas- de innovaciones léxicas (algunas testimoniadas por vez primera; otras, efímeras), de crudos latinismos, tanto como de derivados latinizantes, cuya formación habrá de atribuirse a él mismo. Baste citar unas pocas muestras representativas: accidentario, colateral, conservativo, exhalación, fallencia, ferruginea, fluxible, labrocería, longinquidad, longíssimamente (Venegas prodiga con una reiteración insólita para su época el superlativo sintético), reverberación, terrestreidad, vitulo. Sin embargo, con frecuencia aduce junto a las voces latinas las castellanas contemporáneas, como si quisiera equipararlas, en un intento muy acorde con su propósito educativo: «No significa más princeps en latín que el principal en roman- 
ce» (Agonía, liv r) - «El tiempo del diluculo, que los vulgares dizen ell alua» (ib., lxiv $r$ ).- «Superficie cóncava es to que en romance dezimos envés» (Diferencias, xlvii $v$ ). - «Se dize conuexa que significa comba en romance» (ib., xciii v).- «Línea, que en romance dezimos raya» (Declaración, F viii. Aunque él mismo utiliza liña en otros pasajes). También, aunque con parsimonia, despliega un triple contraste idiomático: «Esta virtud en griego se dize philantropia, y humanitas en latín; en romance se dize affabilidad» (Agonia, clv v).- «Cometa en griego tanto quiere dezir como crinito en latín, y encabellado en castellano» (Diferencias, lxxxiv $r$ ). Menos todavía, pasa directamente del griego al castellano: «En griego se dize metagrapho, y en romance, trasunto o traslado" (Diferencias, xxxi v).

En sentido opuesto, no desdeña el recurso, con propósito ilustrativo, al habla rústica: «En latín se dize defectus, y en romance falta [...], que en las aldeas dizen fallas» (Declaración, E iv).- «Vaga planicies es lo que en las aldeas llaman exido, adonde sale la gente del pueblo a espaciarse» (ib., $G$ vi). - "Pruina, que es la elada que amanece en los tejados y campos, que los labradores dizen escarcha» (Diferencias, lxxviii $r$ ).

18. Las peculiaridades recién enunciadas se entremezclan a lo largo de la exposición con otras de muy distinto carácter. Si se quiere, como transición hacia la última citada, podía ser interpretada una muy prodigada por Venegas: la constatación de su marcado gusto por refranes y sentencias vulgares. Más lo es todavía hacia locuciones populares, generalmente introducidas por como dizen. He aquí unos reveladores testimonios: «Debaxo del sayal, ay al» (Declaración, D i). - «Pies en las manos, es refrán castellano» (ib., F vi).- «Duelo ageno, de pelo cuelga» (Diferencias, xxxviii v).— «Si no ay miel en la orça, que la aya en la boca» (ib., xlii $r$ ). - «Pagarte, como dizen, en la misma moneda» (ib., xiv $r$ ). - «Gobierne, como dizen, calla callando» (ib., xvii $r$ ).- «Peor de salirse afuera que, como dizen, el gato de la assadura» (ib., xlvi v).- «La cree firmemente, como dizen, a carga cerrada» (ib., cxxix $r$ ).- «El refrán que dize: Dios me dé contienda con quien me entienda» (ib., cxxvi v). «Y, como dizen, luchasen a braço partido» (ib., cxcii v).

19. Si de la forma expresiva se pasa al examen de las referencias contenidas en el interior de sus obras, se ve la sostenida compatibilidad con una atención entrañable hacia su ciudad, es decir, el arraigado toledanismo de Venegas, manifiesto en alusiones a personas, lugares y sucesos de su entorno urbano. Así queda patente en pasajes como los siguientes:

«No se oya sino a los que estaban de cerca, assí como en el relox de la Santa Iglesia de Toledo» (Ortographía, 62).- «Vimos en el año pasado de mil quinientos y treinta y seis que, al principio del mes de enero, se heló Ta- 
jo en tanto rigor que [...] le pasaron a nueve de enero más de cincuenta personas a la par, de lo cual yo soy testigo [...], e jugaron en él a los birlos y al herrón y hizieron lumbre y asaron carne» (Agonía, cclvii a).- «Pongamos exemplo: Si queremos saber qué distancia tiene Toledo [...], hallaremos que tiene onze grados de longura» (Diferencias, lxi $r$ ). - «Tanto dista Toledo de la equinoctial quanto el norte se alça sobre Toledo» (ib., lxi v).— «Como en Toledo dezimos las tendillas de Sancho, bien aya, que no son aora más suyas que mías» (ib., lxviii $r$ ).- «Pues estamos en esta ciudad de Toledo, que es el primado de las Españas, sin menoscabo de los presentes, pongamos aquí un exemplo que todos sabemos y vimos en esta ciudad [...]: la solicitud de la gobernación que en esta ciudad tuvo [...] don Pedro de Navarra, siendo corregidor». Y, a continuación, se detiene a enumerar, con toda puntualidad, tanto sus obras benéficas como las urbanísticas, que menciona nominalmente: Alhóndiga, Plaza del Ayuntamiento, Puerta de Visagra, etc.) (ib., clxx r).

20. Me he entretenido en esta caracterización intelectual y social de la personalidad de Venegas para, sobre ella, proyectar el examen de su comportamiento ante las formas verbales con $-i e$ -

En Ortographía, las ocurrencias de -ie- suman un total de 33, frente a las 110 de $-i a-$. Las formas en -ie-nunca llevan pronombre enclítico. No es de extrañar, por la propia frecuencia de uso y la naturaleza del texto, que ambos alomorfos estén más representados en el imperfecto que en el condicional; que la tercera persona de singular prevalezca sobre la de plural; que la primera de singular y las dos de segunda no se atestigüen; que la primera de plural sólo tenga dos ocurrencias, en el imperfecto, con -ie-.

Un recuento total y comparativo de todas las formas examinadas se muestra en el siguiente cuadro:

\begin{tabular}{lrrrr}
\hline Alomorfo -ie-: & $3 .^{\mathrm{a}}$ & $4^{\mathrm{a}}$ & $6 .^{\mathrm{a}}$ & total \\
imperfecto & 14 & 0 & 5 & 19 \\
condicional & 7 & 2 & 5 & 14 \\
total & 21 & 2 & 10 & 33 \\
\hline Alomorfo -ia-: & & & & \\
& $3 .^{\mathrm{a}}$ & $4 .^{\mathrm{a}}$ & $6 .^{\mathrm{a}}$ & total \\
imperfecto & 63 & 0 & 25 & 88 \\
condicional & 14 & 1 & 7 & 22 \\
total & 77 & 1 & 32 & 110 \\
\hline
\end{tabular}


21. Hay pasajes en que las formas con -ie- tienden a agruparse. Por ejemplo, en esta secuencia verbal se presentan: servia ... escrevia ... ponia ... serie ... podriemos ... avie (34), o como en: paresceria ... seria ... avie ... avien ... podian (74). Mientras que en otras figuran testimonios muy aislados: dezian ... dezia ... sabia ... avie ... cogia ... hazia ... oya ... dezia ... despedia ... hazia ... podria ... avia (62).

En cuanto a la posición del acento en el grupo vocálico, la inflexión de la vocal precedente, que en principio, supondría la acentuación -ié-, sólo la acusan los dos únicos casos de tinie, frente a los siete de tenia.

22. Expuestos los varios aspectos de la presencia de -ie- en la Ortographia, la obra temprana de Venegas, la situación estadística de las correspondientes formas puede resumirse así: tales formas con -ie- representan algo menos de un tercio de las etimológicas con -ia-.

23. Para Agonía, la existencia de una amplia sucesión de ediciones permite un análisis más ilustrativo que en el caso anterior.

He inventariado todas las formas con -ie- de la primera edición y luego he procedido a observar la suerte que han corrido en algunas posteriores. Para ello he visto y cotejado, siempre por las ediciones originales, la mencionada primera $(1537)^{37}$, segunda $(1540)^{38}$ y tercera $(1543)^{39}$; desde ella he saltado hasta la sexta (1553), última publicada en vida del autor, precisamente por esta circunstancia. Todas fueron impresas en Toledo, por Juan de Ayala.

El resultado de mi examen comparativo queda reflejado en el siguiente cuadro:

37 La edición de M. Mir, en Escritores místicos españoles, Madrid, Bailly-Baillière, 1911, págs. 105-318, que dice atenerse a ella, es muy defectuosa, según ha demostrado cumplidamente I. Adeva, El Maestro ..., 187-191, circunstancia que obliga a consultar la prínceps.

38 Corregida nuevamente por el mismo autor, según se indica en la cubierta. En el colofón, 15.V.1540, informa Venegas de que no tuvo tiempo de corregir la primera edición; que no se hallaba en Toledo al comenzar la impresión de esta segunda, por lo cual no pudo tampoco corregir los primeros cuadernos, pero si los otros.

Con independencia de la cuestión aquí estudiada, a la que afectan, como puede comprobarse, escasas modificaciones, cabe observar que, en efecto, hubo correcciones materiales o cambios, como se ve en bastantes casos, de los que cito algunos, por lo general meras enmiendas de erratas: dizen (lxxii $v$ ) es remplazado por dizien, pues está incurso en una secuencia enumerativa en que los demás verbos son imperfectos; tempaldo (cxxix $r$ ) es remplazado por templado; natuturalmente (xliv $v$ ) es remplazado por naturalmente; etc. Otro tipo de correcciones afecta a la foliación: en la primera edición se repite el folio cxxvi, al que siguen dos sin marcarla y a éstos el cxxxi, es decir, no se altera el total de hojas del volumen, pero está equivocada la numeración, que en la segunda edición se presenta debidamente establecida.

${ }^{39}$ Nuevamente corregida y añadida por el mismo autor. En efecto, en esta aparece por vez primera, como antes advertí, con portada independiente, la Breve declaración ... 


\begin{tabular}{llll}
\hline $\mathbf{1 5 3 7}$ & $\mathbf{1 5 4 0}$ & $\mathbf{1 5 4 3}$ & $\mathbf{1 5 5 3}$ \\
avie & avie & avia & avia \\
avien & avie & avie & avia \\
avien & avien & avien & avien \\
podrie & podrie & podrie & podrie \\
avie & avie & avie & avia \\
avie & avie & avie & avia \\
avie & avie & avie & avia \\
avies & avies & avies & avies \\
podriemos & podriemos & podriemos & podriamos \\
avien & avien & avien & avian \\
avie & avie & avie & avia \\
salien & salien & salien & salien \\
tinie & tenie & tinie & tenia \\
tinie & tenie & tenia & tenia \\
movien & movien & movien & movien \\
avie & avie & avie & avia \\
tinien & tenien & tenien & tenian \\
tendrien & tendrien & tendrien & tendrien \\
hazien & hazien & hazien & hazian \\
diz(i)en & dizien & dizien & dizien \\
avien & avien & avien & avian \\
avien & avien & avien & avian \\
avien & avien & avien & avian \\
avien & avien & avien & avian \\
avien & avien & avien & avien \\
\hline
\end{tabular}

24. Según se advierte en la tabla precedente, Agonía presenta la novedad, respecto a la presencia de -ie-, de una ocurrencia de la $2 .^{a}$ persona de singular (avies); hay otra de la escasa 1. ${ }^{\mathrm{a}}$ de plural (podriemos), casualmente en el mismo folio (xlviii $v$ ). Sigue sin documentarse, como en Ortographia, la $2 .^{a}$ de plural.

La posible inflexión de la $e$ radical en los tres testimonios iniciales de tinie(n), se restituye, según refleja el cuadro precedente, a $e$ en sus correspondientes apariciones de 1540 y se vuelve a $i$ en un caso de 1543; los otros dos mantienen $e$, uno con terminación -ie- y otro ya con terminación -ia-; finalmente, en 1553 , los tres presentan $e$, coincidente con la vuelta de todos ellos a -ia-. El proceso recién observado confirma lo advertido en Ortographía y previene de la excesiva confianza con que se acostumbra a averiguar la disposición acentual por medio del resultado, efectivo o no, de la posible inflexión. Dizien conserva, obviamente su $i$ inicial etimológica.

Como en Ortographía, a veces se entremezclan ambos alomorfos en un mismo pasaje: el folio lxi $v$ contiene 4 imperfectos en -ie- y 3 en -ia-; en 
lxxii $v$, entre dos apariciones de avien se encuentra una de avian; en $\mathrm{xx} r$ el mismo sujeto gramatical lleva primero podrie y, enseguida, querria.

25. La conversión de las 25 formas en -ie-, existentes en la primera y segunda edición de Agonía, a -ia- apenas se deja sentir en la tercera, pues se mantienen intactas 23; en cambio, su sustitución por el alomorfo es drástica en la sexta, donde se encuentran solamente 8 apariciones con -ia-.

Frente a las citadas 25 ocurrencias de -ie-, en su momento de máxima presencia, las formas con -ia- suman 296. La proporción entre aquéllas y éstas llega a ser en Agonía superior a 1/12, frente a $1 / 3$, como quedó establecido en Ortographía. Con todo, estimo revelador del espontáneo arraigo de -ie- el hecho, advertido en una nota anterior, de que al verse obligado Venegas, por obvia incongruencia sintáctica, a efectuar una corrección en determinado pasaje de la 3 . $^{\mathrm{a}}$ edición, introduzca el alomorfo dizien, pese al presumible cuidado inherente a una operación de tal naturaleza.

La conclusión más importante que se desprende del examen de Agonia es, sin duda, ésta: la progresiva o, con mayor exactitud, acelerada reducción del alomorfo -ie-, siempre menos frecuente, ya seriamente amenazado de desaparición.

26. El síntoma recién expuesto se revela asimismo en la Breve declaración, texto que, recuérdese, si bien se incorpora a la 3.a edición de Agonia, responde a una nueva e independiente redacción. En este tratadillo, entre 138 ocurrencias de imperfectos y condicionales en -ia-, únicamente está empleada su variante en devrie ( $\mathrm{B}$ iii) y sabien ( $\mathrm{F}$ viii).

27. Tras el recorrido analítico efectuado sobre la presencia de las formas en -ie-registrada a través de las obras de Venegas, procede llegar a un juicio de carácter general.

Aunque siempre proporcionalmente escasas, hasta llegar a la desaparición, su existencia, bien atestiguada, no deja de causar profunda extrañeza, sin duda a causa de las ideas dominantes sobre este punto de la morfología histórica verbal. Pero también y de manera principal, dada la formación cultural de Venegas, por comparación con la ausencia, identificada como normalidad, de dichas formas en innumerables textos contemporáneos castellanos de cualquier procedencia regional.

Más. La extrañeza se acrecienta cuando se repara en la dedicación profesional de Venegas: el examen, bajo sus diversos aspectos, de numerosos libros contemporáneos ( $\S 16$ ), en los cuales había de percibir la discrepancia en que incurrían los suyos. $\mathrm{Y}$, sobre todo, por su condición de autor de un erudito tratado ortográfico (aunque no verse sobre la lengua castellana), materia dentro de cuya competencia cabe incluir, según las ideas contemporá- 
neas, una cuestión como la examinada. Precisamente en el prólogo de su Ortographía inserta Venegas esta atinada advertencia sobre una diferenciación fonética, coincidente en su representación gráfica con aquélla: «De otra suerte pronuncia el castellano la última $a$; y de otra manera la pronuncia el francés, que ni bien dize $a$, ni bien dize $e$, mas haze un sonido que entre la $a$ y la $e$ hallarán los curiosos que de industria lo quisieren miran» (6). En otro pasaje, con carácter de generalización, manifiesta la siguiente postura: «Todo nuestro intento es dar reglas de bien pronunciar, porque la razón del escrevir está junta con el hablar, y la escriptura no es otra cosa sino una habla pintada, por donde aprendemos la verdadera pronunciación» (61).

De su atención a los aspectos puramente formales de la impresión tipográfica, aparte de declaraciones, algunas antes copiadas, sobre su cuidado por la revisión de pruebas de sus propias obras, en la Ortographía deja también indicaciones como ésta: «La $x[\ldots]$ en algunos moldes de Alemania viene antepuesta a la $t$. Quando en fin de ringlón parte este nombre dexte$r a$, empieça el siguiente ringlon con xtera. Ellos vean sobre qué se fundan. Nosotros seguimos la razón y el authoridad de los doctos» (29).

No parece, pues, verosímil creer que la presencia de -ie- en sus obras pasase inadvertida a Venegas, ni que fuese ajena a su voluntad (es decir, que hubiera de achacarse a los operarios de las imprentas). Por tanto, habrá que tenerla, como poco, propia de su ideolecto.

28. Las precedentes consideraciones conducen a concluir que, por encima de cualquier otro posible factor, la utilización de -ie- en un autor de las características personales de Venegas ha de interpretarse como debida a su natural práctica del uso toledano. El rasgo regional se encontraba bien arraigado en su idiolecto, hasta el punto de competir con el seguimiento de una norma contemporánea más amplia (imperfectos y condicionales en -ía), que no podía resultarle desconocida.

El comportamiento idiomático de Venegas confirma hasta qué alto grado eran ciertas las apreciaciones de Villalobos y de Correas sobre la citada peculiaridad toledana. Si persistía en un hablante del máximo nivel cultural, puesto que llegaba hasta sus manifestaciones impresas, cuánto más sería su enraizamiento y continuidad en otros estratos sociales.

Desde un nuevo punto de vista, más abierto, con una perspectiva ensanchada, la coexistencia de alomorfos en Venegas no llegará a sorprender tanto, pues admite ser incluida en un aspecto de su lengua: la variabilidad, manifestada a través de un amplio repertorio de fenómenos diversos. Sin necesidad de un examen sistemático ni detenido de esa característica, sus inseguridades y vacilaciones quedan patentes en la duplicidad de soluciones que afecta a un elevado número de voces, no ya en unas obras respecto de 
otras, sino aun dentro de una misma página, con separación de pocas líneas. Véase esta variedad en unas cuantas muestras de diferente naturaleza: cizaña zizaña, linea liña, pluvia lluvia, alvañil alvañir, perfection $\sim$ perficion, alhajas $\sim$ halhajas, çaguan $\sim$ açaguan, çaquiçamis $\sim$ çaquiçamies, el nada la nada, primer dia primero dia, etc.

29. La progresiva desaparición de -ie- en Venegas bien puede explicarse sencillamente como razonable acatamiento voluntario - y hasta cabria juzgarlo inevitable - ante la norma general del español contemporáneó, aunque el hábito propio de su ideolecto le traicionase algunas veces (cf. en especial la inesperada anomalía apuntada en $\S 24$ ). Las circunstancias externas acabaron surtiendo efecto. De modo que el proceso de extinción del alomorfo -ie- aparece totalmente consumado en Diferencias ${ }^{40}$, cuyo texto no inserta ningún testimonio de él, pese a la normal aparición de imperfectos y condicionales (valga esta reducida muestra: 27 ocurrencias en los 10 primeros folios).

30. No existe verdadera necesidad de entrar en causas o condiciones más precisas o particulares que la acomodación a la norma gramatical anteriormente recordada, pues, a mi entender, lo sorprendente radica en la perduración de -ie-.

Ahora bien, el hecho de que la primera obra en que aparece consumada totalmente la extinción haya de datarse, pese a su pie de imprenta, en 1545, autoriza a establecer una conjetura puntual, apoyada en la biografía de Venegas. Su traslado el año anterior a Madrid ( 116 ), donde las formas en -ie(repito que, si se encuentran en la letra impresa de sus obras, obvio es suponerlas espontáneas en su comportamiento lingüístico oral) habrian de chocar, en especial ante su auditorio discente, pudo colocarle en una situación socioprofesional enojosa. Como consecuencia, el público contraste habría resultado de influencia decisiva para obligarle al abandono radical, observado en la edición de Diferencias correspondiente a aquel año, de tales formas verbales, que, sin duda, hubieron de extrañar en Madrid.

\footnotetext{
${ }^{40}$ La ya citada primera edición, Toledo, 1540, ofrece en su datación algunas anomalías que no he visto denunciadas por los bibliógrafos. La primera pieza de los preliminares, está firmada por el Maestro Alonso Cedillo, en Toledo, segundo día de nouiembre 1539 (i v); la segunda, por el propio Venegas, primero de nouiembre de 1539. Nunc autem 1545 (ii v); las restantes, sólo consignan 1539; el colofón es de Toledo, Juan de Ayala, 28.II.1540. A los efectos que aquí interesan, el dato para tener en cuenta es que la explícita corrección del año, 1545 , queda garantizada por el autor, cuando en el interior del libro (xci $v$ ) afirma estar escribiendo el día 10 de marzo de 1545 .

La que parece ser $2{ }^{a}{ }^{a}$ edición, Toledo, 1545 (hay facsímil de D. Eisenberg, Barcelona, $\mathrm{Pu}$ vill, 1983) presenta las dos primeras piezas datadas tal como acabo de citarlas; el colofón es de Toledo, Juan de Ayala, 4.I.1546.
} 
Será oportuno recordar aquí la evolución sobre este punto en su otra obra extensa y más editada, Agonía ( $§ 23$ ). En la edición de 1543 apenas se reducen (de 25 a 23) las formas en -ie- presentes desde la primera edición. En la de 1553 sólo sobreviven 8 de ellas. También para esta secuencia editorial se muestra cronológicamente adecuada la explicación del cambio residencial.

Cabe concluir, confirmando apreciaciones anteriores, que el comportamiento idiomático de Venegas muestra cómo los imperfectos y condicionales en -ie- alcanzaban en Toledo hasta la letra impresa. Si bien su disparidad respecto a la norma general del castellano debió de llevarle a su voluntario abandono, mediado el siglo.

\section{SEBASTIÁN DE HOROZCO}

31. Ya he recordado antes ( $\$ 13$ ), con motivo de un antiguo estudio mío, cómo las obras dramáticas de Sebastián de Horozco registran la presencia, minoritaria, de las desinencias en -ie-. Las circunstancias personales que concurren en este autor aconsejan vivamente completar la visión precedente con el examen de otras obras suyas, que ofrecen, además, la ventaja de pertenecer a géneros distintos.

Nacido en Toledo, hacia 1510, hijo de padres toledanos, la última noticia registrada sobre su vida es de 1580 . Estudió Leyes en la Universidad de Salamanca, donde alcanzó el título bachiller en 1527 y el de licenciado en 1534. En su Teatro universal de proverbios se presenta como «jurisconsulto, vecino de Toledo». Parece que no ejerció ningún cargo de relieve, a juzgar por las actuaciones que de él se conocen documentalmente; que destinaba su tiempo libre, al parecer abundante, a tareas literarias, según sus declaraciones, en las cuales presume de sus dotes poéticas: «Esta gracia y habilidad Nuestro Señor fue servido de me dotar en algo»; y que residió siempre, de modo habitual, en su ciudad nativa, donde murió.

Personas, ambientes, lugares y sucesos de aquélla prácticamente invaden toda la creación literaria y cronística de Horozco y aun se hacen presentes en sus abundantísimos comentarios paremiológicos. Su toledanismo se revela desbordante y radical, siempre ejercido con una perspectiva que apenas sobrepasa las trivialidades de lo cotidiano. Su limitado horizonte vital, a veces trascendido con dudosas intenciones moralizantes, sirve como principal materia prima de sus creaciones, aunque no carezcan de referencias eruditas, denotadoras de un escritor instruido. Este último aspecto queda más destacado, es lógico, en su copiosa tarea de glosar, en prosa y verso, proverbios.

De todos sus libros, voy a examinar el Cancionero, las Relaciones, el Teatro universal de proverbios y el Libro de los proverbios glosados. Poe- 
sía, prosa narrativa, y didáctica, tanto versificada como prosística, respectivamente, servirán para completar la imagen literaria de Horozco. Circunstancia de excepcional importancia común a todas estas obras es que se conservan en manuscritos del autor o próximos a él, sin haber conocido la impresión hasta tiempo reciente.

32. El talante festivo, chabacano y desvergonzado domina la mayor parte de las poesías del Cancionero, factores que atemperan un tanto en ocasiones la virulencia de sus numerosas sátiras y pullas, dirigidas genéricamente a determinadas clases sociales y profesionales, como asimismo a individuos bien identificados, de los que, sin contención, señala defectos físicos y tachas morales. Cierto que también encuentran amplia cabida entre sus composiciones las de vivos sentimientos religiosos y amorosos, debates, adivinanzas, glosas de cantarcillos antiguos, etc.

Tras esta sucinta caracterización del Cancionero, presento los datos que afectan al análisis aquí emprendido.

En el total de la obra poética contenida en aquella recopilación, descontadas, como es obvio, las Representaciones teatrales, antes examinadas ( $\S 13$ ), descubro 156 concurrencias de -ia- por 65 de -ie-. La proporción entre unas y otras supera algo la de $2 / 1$ propia de las Representaciones, pero no llega a ser de $3 / 1$; queda, pues, bastante similar y la igualaría, si no se hubiesen tenido en cuenta los epígrafes de las composiciones, donde las formas en -ia- son las únicas que aparecen. Ni que decir tiene que, por el contrario, he descontado aquellas apariciones que están condicionadas ( 0 , al menos, cabe suponerlo así) por la rima, frecuentes en el caso de -ía-, salvo que rimen con otras formas de imperfecto y condicional, pues a efectos métricos podría haber recaído la elección igualmente a favor de las formas en -ie-, que en esta posición resultan muy escasas. Como también que dicha desinencia, pero bajo el esquema acentual -ié-, se presente en rima con palabras de otra especie, circunstancia que sólo queda documentada en 2 casos: avié $\sim$ fe (n. 172); harié edificaré (n. 277). Esta limitación en la distribución de -ie- no ha de extrañar, pues tanto -ié- como -ie- ofrecen menos posibilidades para la consecución de una rima.

Los 63 casos restantes, es decir, los atestiguados en interior de verso, todos ofrecen la acentuación -ié-. Parece claro que con ella, a efectos de escansión, se busca el monosilabismo del grupo vocálico, propiedad que falta a $-i a-$.

Detallada la muestra estadística, la neta distribución entre -ié- (63 casos) $\sim$-ie- ( 2 casos, ambos en posición final) confirma plenamente el factor electivo ya observado anteriormente en el habla de Horozco ( $§ 13)$. El elevado número de apariciones descarta, a mi juicio, la suposición de que -ié- 
obedezca a sinéresis. Antes bien, ha de tenerse por variante morfológica con plena vigencia.

Algunas circunstancias particulares en la distribución quizá pudieran servir para justificar la alternancia alomórfica en determinados pasajes, pero no debilitan el propuesto principio métrico que parece predominar en la aparición de -ié-.

En varias ocasiones ambas variantes se presentan casi contiguas: «Según los años avía / que avié muy gran sequedad» (n. 12).-- «Si me dexases, sería. / Serié muy vana porfía» (n. 299). En casos como los recién consignados, cabría pensar en el propósito de evitar la rima interna. Es posible, pero, ciertamente, no siempre se evita: «Referían que dezía» (n. 316).

En otras ocasiones, las formas en -ié- se encuentran próximas entre sí, parece que tienden a agruparse: «Pues que podrién dar consejo, / dirién de vos, si hablasen» (n. 41); «Que avié de venir camino / lo que avié de remojar» (n. 175).

También, por el contrario, su presencia queda a veces muy aislada: $m a-$ ravillaría ... serién ... paçía (n. 14); serié (n. 43) aparece en un copla real que contiene, entre imperfectos y condicionales, seis testimonios de -ia-. En otra (n. 368), tras 4 apariciones de -ia- siguen 2 de -ié-.

Merece destacarse, por su escasez histórica, la existencia de la 1. a persona de singular, avié (n. 138 y n. 299); por faltar en las Representaciones, la 1.a persona de plural, aviémos (n. 269); la 2. a persona de plural, como en aquellas obras dramáticas, conserva la $-d$ - desinencial: podriédes (n. 44), abiédes (n. 53).

Según Weiner, especialista en Horozco, su Cancionero «tiene bastante buen orden cronológico y cubre casi cincuenta años» de su vida. De ser así -el editor no aduce ninguna razón para justificar su primer aserto-, las formas en -ié- resultarían apenas predominantes en la fase inicial, pero pronto Horozco las habría ido eliminando, a juzgar por estos recuentos estadísticos parciales: en las primeras 50 composiciones se encuentran 14 casos de -ié-frente a 13 de -ía-. Al llegar a la composición n. 100, ya se ha invertido la relación: -ié- ha crecido sólo hasta 4 unidades más; -ia-, hasta 13. En adelante, la desproporción se va haciendo más acusada cada vez

33. Horozco escribió diversas memorias, relaciones, noticias, etc., sobre asuntos muy dispares y en épocas también muy varias ${ }^{41}$. La mayoría de estos textos prosísticos son traslados, como dice el propio Horozco, de documentos ajenos; otros parecen acusar semejante origen; a algunos sí cabe atribuirles que su redacción se deba plenamente a Horozco. El conjunto resulta, pues, de dudosa seguridad para cuestiones como la aquí examinada.

${ }^{41}$ Conocieron una publicación dispersa hasta que las reunió J. Weiner bajo el título de Relaciones históricas toledanas, Toledo, IPIET, 1981. 
Conocidas estas circunstancias, consigno que en toda la recopilación sólo he hallado dos testimonios de las formas buscadas: entendie (64) y escribie (65), ambos en la copia que Horozco efectúa de un estatuto promulgado por el Arzobispo y el Cabildo catedralicio de Toledo en 1547. Ni que decir tiene que las formas verbales en -ía- son incontables.

34. En su Teatro universal de proverbios, cuyo manuscrito más autorizado, quizá autógrafo, según su editor ${ }^{42}$, ha de datarse entre 1558 y 1580 , Horozco glosa 3.137 refranes. Para la mayor parte, el comentario a cada uno se encierra en una copla real, pero con alguna frecuencia se extiende a más de una y llega hasta catorce. Calculo que el total de versos debe de estar en torno a los 35.000 octosílabos. Las formas en -ia- predominan claramente sobre las formas en -ie-, según se percibe en una simple lectura.

Para un cómputo más preciso y relevante del empleo de ambas formas, he tenido en cuenta criterios similares a los que he aplicado ya a las anteriores obras de este autor. Prescindo, como es obligado, de los proverbios o refranes; me limito al texto de la glosa. Prescindo asimismo de las apariciones que se presentan en rima con otra palabra ajena a su caracterización morfológica, sólo coincidente en la materialidad del tramo versal de la rima, pues pueden estar provocadas para satisfacer ésta. Admito, en cambio, los casos en que la rima se produce entre verbos con las indicadas desinencias, puesto que la decisión de preferir una u otra, carente en absoluto de un condicionamiento como el precedente, surtiría idéntico efecto. En interior de verso, señalo todas las ocurrencias, si bien anticipo que la alternancia cuenta generalmente con una explicación.

Con estas salvedades, descubro que la presencia de la terminación -ia- alcanza, salvo error en mi suma, a 238 unidades. Éstos son todos aquellos casos en los cuales la elección del alomorfo no parece estar sometida (aún he de precisar mejor esta cuestión) a imposición de ningún tipo. Ahora bien, a ellos hay que añadir 19 más, en interior de verso, con la particularidad de constituir una secuencia monosilábica, es decir, de responder a la acentuación -iáa, según demuestra la escansión de los versos en que se aloja.

El alomorfo -ie- siempre presenta el esquema acentual -ié-. En interior de verso, donde su empleo puede estimarse menos supeditado a exigencias formales, queda atestiguado en 35 casos. En posición final de verso, asimismo siempre fonéticamente -ié-, encuentro 21 casos, pero queda la sos-

\footnotetext{
${ }^{42}$ S. de Horozco, Teatro universal de proverbios, ed. de J. L. Alonso Hernández, Universidad de Groningen, 1986. Otro manuscrito, que el editor describe, sin datarlo, corrige bastantes veces -ie-por -ia- o lo sustituye por la terminación de otro tiempo verbal, con inadmisible distorsión gramatical, si no introduce una enmienda de mayor alcance aún. Este comportamiento descubre que -ie- resulta totalmente inaceptable.
} 
pecha de que su empleo haya sido motivado por conveniencia de rima. Si pese a esta circunstancia los consigno, es para mostrar su escasa frecuencia total, que contrasta con los numerosos testimonios de -ia- no computados, según advertí, para la misma finalidad de empleo. En una consideración absoluta, tampoco ha de extrañar la desproporción: huelga repetir que las posibilidades de rima en -ia- resultan incomparablemente más altas que las de $-i e ́$ - (o del posible, pero inexistente -ie-).

Queda, pues, manifiesta la considerable superioridad numérica de -ia-. En el mismo sentido, aun cabe aducir que así como son relativamente numerosas las rimas obtenidas por la presencia concurrente de imperfectos o condicionales marcados por -ia-, en ninguna ocasión se produce ese efecto por medio de -ié-, que hubiera rendido idéntico servicio a la construcción del verso.

Algunas observaciones particulares, varias ya indicadas a propósito de las otras obras. No resulta excepcional que en una misma estrofa concurran ambas variantes. La existencia de una tercera variante, -iá-, en mínima proporción respecto de las otras, admite la fácil explicación de deberse a un compromiso más o menos consciente, entre las dos anteriores. Interpretar dicha variante como recurso a una licencia métrica, sinéresis, me parece menos probable. Pues para conseguir el cómputo monosilábico del grupo vocálico contaba el versificador con el frecuente alomorfo -ié-.

Aunque, por la tonalidad de Teatro, la mayor presencia de la $3 .^{a}$ persona de singular respecto de las restantes personas verbales resulte aún más explicable que en las restantes obras, con las cuales coincide en esta característica, observo una diferencia: las formas en -ié- afectan a la totalidad de aquéllas. Destaco el arcaísmo morfosintáctico llevarloyé (n. 2836).

En conclusión, Horozco descubre su decidida preferencia por el alomorfo -ia-. El empleo de -ié- bien puede atribuirse a conveniencias métricas. El predominio de -ia- se acrecienta durante el trascurso de la obra. En las 400 primeras composiciones, guardadas las restricciones antes establecidas, la proporción entre -ia- / -ié- es de 4'5/1; en las 100 últimas ha ascendido hasta 13'5/1. El Teatro universal de proverbios, con su gran extensión y correspondientes recuentos elevados, al mostrarse coincidente con la caracterización general observada en las obras anteriores de Horozco, supone una definitiva confirmación tanto de la vigencia de -ie- como de la tendencia cronológica creciente ${ }^{43}$ que se observa en él hacia la parquedad en su empleo.

43 Dicho sea con las salvedades que deben guardarse, pues obras como el Cancionero o el mismo Teatro universal de proverbios, por su propia naturaleza habrán de contener piezas de diversos momentos. Así resulta patente en otra obra de Horozco a la que enseguida me referiré, de similar desarrollo. Con todo, sí queda claro que en el interior de cada obra individual, aunque no quepa asegurar que el orden de sus componentes responda al cronológico, disminuye progresivamente la presencia de $-i e$-. 
35. Queda aún por examinar otra extensísima obra de Horozco, el Libro de los proverbios glosados, de igual género que la recién analizada, pero de muy distinto carácter. Según su editor ${ }^{44}$, de acuerdo con algunas indicaciones temporales explícitas que suministra el autor, más otras indirectas, su composición debió de trascurrir entre los años 1570 y 1580 . La tonalidad burlesca y socarrona de Teatro universal de proverbios ha desaparecido y el texto queda dominado por una apelmazada erudición. Pero, sin duda, la diferencia mayor entre ambos comentarios paremiológicos, de especial relieve para el examen presente, radica en que el segundo está compuesto en prosa.

Inmediatamente debo añadir que el Libro de los proverbios glosados no presenta ningún testimonio de -ie-, pese a la copiosa aparición de imperfectos, como, en menor número, de condicionales. Esta caracterización negativa viene a corroborar el papel decisivo que antes atribuí a las conveniencias métricas en el empleo del alomorfo -ie- (sin dudar de su realidad natural: basta recordar su presencia en la prosa dę Venegas). Recuérdese, por el contrario, que dicho alomorfo se encontraba también prácticamente ausente de la otra obra prosística de Horozco, las Relaciones (y aun podía dudarse de que los dos testimonios registrados correspondieran a Horozco). La señalada inexistencia de -ie- en el Libro de los proverbios glosados también concuerda, por la data tardía de su composición, con mi antes indicada observación de que su empleo decae en Horozco con el paso del tiempo.

En este último aspecto, estimo significativo que idéntica decadencia, hasta la desaparición, experimentan, según descubrí, las obras y ediciones de Venegas.

\section{GARCILASO DE LA VEGA}

36. La obra poética de Garcilaso de la Vega, nacido, al igual que Horozco, en fecha incierta, pero sin duda algunos años, muy pocos, antes que él, dada la brevedad de su vida, es - aquí sí cabe la seguridad - anterior a la de su paisano. Pese a esta circunstancia, he pospuesto su examen, pues en ella concurren, bien conocidas, varias otras de decisiva consideración a la hora de establecer, aun implícitamente, cualquier comparación entre ambas manifestaciones literarias. La adscripción del quehacer garcilasiano a una poética innovadora; los problemas de fidelidad textual ${ }^{45}$ que plantea la

\footnotetext{
44 Sebastián de Horozco, El libro de los proverbios glosados (I570-1580), ed. de J. Weiner, Kassel, Reichenberger, 1994, 2 v.

${ }_{45}$ Cuando en el presente estudio me refiero al texto garcilasiano, al manuscrito de Garcilaso, etc., antes de su impresión, no prejuzgo la naturaleza (autógrafo, apógrafo, etc.), tan debatida por los garcilasistas, del traslado recibido por Boscán.
} 
transmisión de su obra, etc., hacen aconsejable, a mi entender, anticipar los presumibles puntos de referencia.

Por de pronto, dejo constancia de los siguientes datos patentemente verificables.

En posición de rima, imperfectos y condicionales aparecen con frecuencia, hasta sumar, en total, 149 incidencias, que, en la mayoría de los casos, riman entre sí. El interés cuantitativo de este recuento le viene por comparación con la presencia de tales tiempos verbales en interior de verso, donde cabría esperar una cifra más elevada y, sin embargo, sólo se encuentran 52 incidencias.

Ahora bien, el dato relevante para la finalidad aquí perseguida radica en la siguiente distribución de las formas examinadas, pues tanto uno como otro tiempo verbal admiten diferente esquema acentual: -ia- en unos casos, por contraste con -iá- en otros. De acuerdo con esta posibilidad, se descubre el siguiente criterio, parcial, de distribución. Las realizaciones verbales que llevan desinencia aguda no se encuentran nunca en posición final de verso. Así, pues, las 149 formas de imperfecto y condicional que, como señalé poco antes, ocupan posición final en el total de versos garcilasianos, corresponden siempre a la acentuación -ía-. En interior de verso, por el contrario, esta variante desinencial resulta minoritaria, de modo que del total de las 52 incidencias antes contabilizadas en esa posición, corresponden 35 al esquema acentual -iá- y 17 a $-i a-$.

Se observa también que un mismo verbo admite conjugarse con una u otra de las dos variantes (indico entre paréntesis el número de apariciones): avía (4) aviá (14), parecía (9) pareciá (2), tenía (5) teniá (4), solía (12) soliá (1), etc.

37. Para la primera distinción establecida (posición en el verso) existe una segura y sencilla explicación, si se tienen presentes algunas exigencias formales que caracterizaban la poética italianizante, aceptadas con gran fidelidad por Garcilaso, según es sabido y enseguida habrá ocasión de comprobar aquí.

Antes será oportuno recordar que las palabras con acentuación oxítona, en general, ya habían sido insistentemente repudiadas por Nebrija ${ }^{46}$ : «Como diximos arriba: Proprio es de la lengua castellana tener el acento agudo [entiéndase: principal] en la penúltima sílaba o en la última cuando las diciones son bárbaras o cortadas del latín». Poco después calificará de diciones peregrinas a las palabras que terminan en $a$ tónica.

\footnotetext{
${ }^{46}$ A. de Nebrija, Gramática castellana, $19 r$.
} 
De la aversión, entre los cultivadores de la innovación poética renacentista, a que la última sílaba del verso fuese acentuada, da cuenta Lapesa ${ }^{47}$ en estos términos: «El fino sentido artístico de Garcilaso hizo que tan pronto como entró en pleno contacto con la poesía italiana, donde los versos oxítonos eran sumamente raros, los proscribiera de la suya. Aún los admitía en 1532, pues la canción III muestra cuatro finales agudos en 73 versos; pero no hay ninguno en los más de 3.500 versos atribuibles con seguridad a los años 1533-36, cuando el poeta residía habitualmente en Nápoles».

Puede, pues, sostenerse que Garcilaso tuvo bien presente la rigurosa aplicación de este criterio ${ }^{48}$ a la composición de las tres églogas, las dos elegías, la epístola a Boscán, la canción $\mathrm{V}$ y la mayoría de los sonetos. El no haberlo atendido, por ejemplo, en el caso del verso 12: $\mathrm{A} \mathrm{mi} \mathrm{s}^{\prime}$ an de tornar (en rima con estar), y en otros varios, de la canción II, «la más abundante en versos agudos», explica la reacción, entre magisterial y exculpatoria, de Herrera ${ }^{49}$ :

Los versos troncados o mancos, que llama el toscano, i nosotros agudos, no se deven usar en soneto ni en canción. $\mathrm{Y}$ aquí no son de algún efeto, antes están puestos a caso, i no es admiración, porque G. L. no halló en su tiempo tanto conocimiento de artificio poético, que su ingenio lo levantó a mayor grandeza $\mathrm{i}$ espíritu que lo que se podía esperar en aquella sazón. Pero [...] si no muestran [...] algún espíritu i sinificación de lo que tratan, son dinos de reprehensión.

A Rico ${ }^{50}$ se debe un detallado estudio sobre los motivos que habían afianzado y extendido la doctrina recién expuesta. Toma como punto de partida la resignada protesta de Hernando de Hoces, en su traducción de Los Triumphos de Francisco Petrarcha (Medina del Campo, 1554), quien lamenta cómo se iba imponiendo la ley de los metros venidos de Italia, según la cual habían de «fenecer todos los versos en vocal y que ninguno tenga el accento en la última». Su investigación, cuyos puntuales pasos eruditos no cabe resumir aquí, facilita comprender con mayor precisión el comportamiento métrico observado por Garcilaso en la composición de sus poesías.

${ }^{47}$ R. Lapesa, La trayectoria poética de Garcilaso, ed. corr. y aum., Madrid, Istmo, 1985, pág. 184.

${ }^{48}$ Consigna Lapesa estos datos procedentes de Keniston: se han contabilizado catorce rimas agudas en Dante, una sola en Petrarca y dos en Ariosto.

49 F. de Herrera, Obras de Garci Lasso de la Vega con anotaciones ... Sevilla, 1580, pág. 232.

${ }_{50}$ F. Rico, «El destierro del verso agudo», Homenaje a José Manuel Blecua, Madrid, Gredos, 1983, págs. 525-552. 
38. El recuento unitario, a efectos del análisis morfológico de las apariciones de imperfecto y condicional, con independencia de su posición en el verso, arroja un total de 166 incidencias para las que llevan la acentuación -ia-, por 35 de aquéllas cuya acentuación es -iá-. A primera vista, parece, pues, indiscutible la preferencia morfológica de Garcilaso. Sin embargo, dicha distribución requiere un previo examen crítico, que obliga a interpretar de distinto modo los datos cuantitativos.

Antes expuse y aquí confirmo con las observaciones de Rico cómo Garcilaso se acomodó a evitar los finales de verso con acentuación aguda. Ahora queda de manifiesto que ajusta asimismo todas sus poesías fieles a dicha norma, poco antes enumeradas, a otra exigencia fónica: la terminación ha de ser vocálica en aquella posición. Ciertamente que a efectos de presentar remate vocálico en los versos, resultaría indiferente el silabeo $i a$ o iá-. Pero la nueva manifestación de respeto ratifica su cabal sometimiento a las exigencias versales de la métrica italiana.

En consecuencia, las restricciones innovadoras que gravan el final de verso dificultan admitir como debida a elección plenamente libre los finales en -ia-. De modo que las 149 formas de imperfecto y condicional que, con ese esquema acentual, cierran otros tantos versos, han de ser descartadas en el análisis de la variabilidad morfológica verbal propia de Garcilaso. Correctamente circunscrito dicho análisis a la forma que presentan aquellos tiempos a través de sus apariciones, incondicionadas, en interior de verso, el resultado invierte la proporción cuantitativa establecida antes, en una primera fase del recuento. Como variante preferida por Garcilaso ha de estimarse -iá-, puesto que el número de contextos libres en que se presenta (35) resulta notablemente superior, el doble, a los de $-i a-(17)$.

Así y todo, percibidas como causantes de irregularidad silábica (hipermetría) las palabras en que se presenta la variante acentual -iá-, los versos portadores de ellas se han sentido necesitados de explicación. Y, de hecho, se la ha buscado para los que cuentan entre sus componentes léxicos con un imperfecto o un condicional dotado de la secuencia -iá-, objeto de advertencia, desde los primeros comentaristas del corpus poético garcilasiano, sobre su constitución silábica. Para todos ellos se apela a considerarlos afectados por una licencia métrica: el recurso a la sinéresis.

Fernando de Herrera así lo declara de forma explícita a propósito del verso: Yo avïa jurado nunca mas meterme (soneto VII, 9). Tras copiarlo bajo tal forma, anota Herrera ${ }^{51}$ respecto de avïa que «este verbo es bissílabo por la sinéresis o contración».

\footnotetext{
${ }^{51}$ Herrera, Obras..., pág. 110.
} 
En el verso: Que m'avïades de ser en algun dia (soneto X, 7) Herrera sigue, como se ve, idéntico criterio que en el caso precedente, ahora sin ningún comentario. En adelante, ya siempre procederá así. De modo que, para los restantes casos, si no de modo explícito, no descuida Herrera la marca diacrítica mediante la colocación de crema sobre la $i$ : hacïa, parecïa, podrïan, etc. Otros editores, hasta el presente, se han preocupado también de indicar la presencia de sinéresis, por lo general mediante distinto recurso gráfico de aquél, consistente en la presencia o la ausencia de tilde acentual: habia / habia.

39. Como en otros textos ya analizados, el neto predominio de una variante, en este caso -iá-, hace poco recomendable, en mi opinión, intentar justificarla como licencia métrica. Así se ha venido procediendo reiteradamente para salvar a Garcilaso. Sostengo, por mi parte, la postura de respeto a su lengua, a una determinada peculiaridad, no exclusiva, de ella, sin repudiarla ni enmendarla porque discrepe del uso general contemporáneo y no haya sobrevivido en el español actual.

A la vista de los resultados ya obtenidos en el estudio presente, no dudo en afirmar con claridad que en Garcilaso convivían dos variantes para la desinencia de imperfecto y condicional: -ia- $\sim-i a ́-$. Polimorfismo sobre cuya validez no encuentro ningún motivo para ponerla en duda. De inmediato, porque en el ideolecto de Garcilaso se descubren bastantes otros casos, de distinta naturaleza entre sí, que reflejan su falta de fijación, entendida simplemente como manifestación de la propia inestabilidad contemporánea: agora $\sim$ ahora $\sim$ ora, mismo $\sim$ mesmo, calor (masculino y femenino), nadie $\sim$ nadi, estoy $\sim$ estó, sintió $\sim$ sentió, queriendo $\sim$ quiriendo, tendrá $\sim$ terná, veía $\sim$ vía, etc. Por eso, dentro de la medida posible, prefiero admitir y respetar la disparidad interna (fonética, gramatical, léxica) antes que recurrir a la sinéresis o a cualquier otra licencia métrica con el fin de ajustar la escansión de sus versos ${ }^{52}$.

Pero, sobre todo, debe constar, a propósito del punto examinado, como argumento decisivo, el poco antes enunciado: la afinidad con otros escritores (paisanos y contemporáneos), de quienes, por razón de indudables diferencias personales y literarias, le suelen aislar de modo más o menos consciente, pero intencionado, las historias literarias. También en ellos se reve-

\footnotetext{
52 No es éste el lugar apropiado para una revisión -otra más, entre tantas bien autorizadas- del texto garcilasiano en cuanto a la nueva imagen aquí creada sobre un particular rasgo morfológico de su lengua. Espero hacerlo en ocasión oportuna. Pero ya cabe apuntar alguna consecuencia: el análisis verificado acrecienta la tan ponderada perfección de Garcilaso. Merced a la tarea realizada se ha vuelto innecesario recurrir en 35 versos a justificar su correcta escansión mediante el recurso a la sinéresis.
} 
laba, según he ido mostrando, variabilidad respecto a la desinencia analizada. Si bien su alomorfismo se manifestaba de manera netamente prioritaria entre -ié- $\sim-i a-$, no falta constancia de la aparición de -iá- en Cota y en Horozco (como asimismo de -ie-, en este último), autores entre los cuales se encuadra, cronológicamente, su conciudadano Garcilaso.

40. Aunque sólo suponga la presentación de una hipótesis, merecedora del reconocimiento que cada estudioso decida otorgarle, aventuro que cabe llevar más allá, hasta la identidad, la manifestada similitud morfológica (coincidencia en -ié-). Para su formulación, me baso, una vez más, en la azarosa trasmisión del texto garcilasiano. Acerca de éste, conocido el estado que ofrecen las obras de muy diferentes, entre sí, escritores toledanos de su tiempo, resulta verosímil suponer que presentaría, en interior de verso, imperfectos y condicionales, algunos, al menos, con la terminación -ié(por descontado, junto a otros con -ia-). He de insistir en la deplorable suerte textual corrida por el manuscrito llegado a las manos de Boscán, con la finalidad de imprimir las obras de su amigo. La condición insólita de tales formas verbales con -ié- en libros españoles (fuera de algunos procedentes de Toledo, como la Ortographia, antes examinada, de Venegas, y, claro está, el considerable predominio de -ia- en el propio manuscrito de Garcilaso) se prestaba a provocar la casi inevitable enmienda de $e$ por $a$, trueque carente de toda repercusión efectiva, pues en nada afectaba a la comprensión o a la claridad (antes al contrario); ni tampoco al ritmo versal, mientras se pronunciase -iá-. La disposición acentual del grupo vocálico no admitía, obviamente, rectificación sin ocasionar, como primera consecuencia, hipermetría. En cualquier caso, estimo superfluo suponer que estos distingos operaban en la imprenta, donde la vista suele prevalecer sobre el oído.

Todavía cabe alegar otra circunstancia, vinculada de manera inmediata con la precedente, a favor de la citada modificación vocálica. Las presuntas formas con - $e$ - podían interpretarse en Barcelona, erróneamente, como catalanismos, dada la presencia en catalán de esa vocal en la terminación del imperfecto de los verbos de la segunda y de la tercera conjugación ( $\mathrm{y}$, por tanto, del condicional). Para quienes intervinieran en la edición de Boscán y Garcilaso, el paradigma, por ejemplo, del imperfecto del verbo 'haber' estaba formado, quizá con alguna explicable variación, irrelevante al objeto actual, del siguiente modo: $a v-i a, a v-i e s, a v i-a, a v-i e m, a v-i e u, a v-i e n$ (actual havia, havies, havia, haviem, havieu, havien). Tales terminaciones eran comunes para todos los verbos de las citadas clases. Perceptores del contraste entre la desinencia -ie- del catalán, su lengua propia, y la desinencia -ia- del castellano, tan abundante en el texto garcilasiano, y, a la vez, de la 
igualdad entre las probables formas toledanas y las catalanas, pudieron provocar la ultracorrección en el texto manejado. De ahí que la presencia de -ie, si se admite mi propuesta, quedase borrada a favor siempre de -ia-.

El hipotético proceso recién descrito encuentra un paralelo, que favorece su credibilidad, en otra enmienda morfológica padecida por el manuscrito garcilasiano. Simplifico aquí lo estudiado por mí con detalle tiempo atrás ${ }^{53}$ : en la edición príncipe se encuentra pretiende, verbo que, a diferencia de la práctica totalidad de los formados sobre tender, no desarrolla, por su tardía incorporación, diptongación de la vocal temática. Esa discrepancia, unida a los numerosos casos en que un verbo castellano presenta diptongo frente a vocal en el correspondiente verbo catalán, indujo erróneamente a atribuírsela también al presumible pretende, como de modo espontáneo corrigieron pronto las ediciones posteriores y los comentaristas, sin juzgar precisa explicación alguna.

\section{LA $A R C A D I A$}

41. Obra tan del gusto de Garcilaso e influyente sobre su poesía, la Arcadia, de Sannazaro, fue impresa, traducida por vez primera al español, en Toledo, el año 1547. La versión corrió a cargo de tres ingenios de dicha ciudad, según informa en la dedicatoria quien, entre ellos, parece haber sido el promotor de la empresa y supervisor de la tarea literaria, Blasco de Garay ${ }^{54}$. Según su declaración inicial, la traducción de la prosa pertenece a Diego López de Ayala, canónigo y vicario de la iglesia toledana. Garay estima que la tarea de este escritor «no va mal arreada, assí de stilo y primor» y su encarecimiento alcanza la más alta cota posible, trasluciendo la fama idiomática contemporánea, pues elogia «su propriedad de hablar, no sólo castellana, mas toledana y de cortés caballero». A su vez, el capitán Diego de Salazar «compuso toda la parte del verso que aquí va, harto más elegante en estilo que atada a la letra del primer author». Con todo, «no dexé de añadir un poco de mi trabajo en lo uno y en lo otro», concluye Garay.

Valga comentar, tras una simple lectura de la Arcadia, sin necesidad de cotejo con el original ni de buscar autorizados juicios ajenos, que el resul-

\footnotetext{
${ }^{53}$ F. González Ollé, «Pretende, no pretiende (Garcilaso, Elegia I, 297)», Homenaje a Luisa López Grigera, Bilbao, 2000, págs. 247-260.

54 Toledano, autor de Cartas en refranes, obra muy difundida. Sus colaboradores, si no son de Toledo, viven en la ciudad (cf. supra), cultivan la literatura y han hecho ya traducciones de autores extranjeros, entre ellos Boccaccio.
} 
tado no me parece tan halagüeño como lo prometían sus autores. La lengua empleada por éstos se presenta reiterada y variadamente marcada por la del original: uso de futuro de indicativo por presente de subjuntivo en diversas clases de subordinadas; disposiciones sintácticas anómalas; adaptación forzada de términos italianos; etc. En cuanto a la versificación, el nuevo ideario poético se vierte, salvo aislada excepción, en los viejos odres estróficos de los cancioneros castellanos y, desde luego, desatendidas las exigencias renacentistas, poco antes expuestas a propósito de Garcilaso, sobre la terminación versal. Estimo que no resulta ocioso consignar estas observaciones antes de encarar la cuestión lingüística aquí estudiada.

En la parte prosística del texto de la Arcadia aparecen, salvo descuido, por defecto, en mi cálculo, 232 formas de imperfecto y 51 de condicionales en -ia- (deberá de suponerse la acentuación -ia-). En contraste con ellas, he encontrado 11 imperfectos y 3 condicionales en -ie-. Este alomorfo se encuentra además dentro de la parte versificada, sensiblemente mucho más reducida que la prosa, en 2 imperfectos y 3 condicionales, todos en interior de verso, salvo uno, que rima con ves. Tanto este último testimonio como la escansión, en los restantes, permiten conocer que para todos los casos la acentuación es aguda, -ié-.

He aquí el repertorio de tales formas, conservada su grafía, según su aparición sucesiva en el libro: auriemos ( $\mathrm{C}$ i v), auie ( $\mathrm{C} \mathrm{v} v$ ), auien ( $\mathrm{C}$ vii $r$ ), viemos ( $\mathrm{D}$ ii $v$ ) (adviértase que la alternancia vía $\sim$ veía es corriente en la época y se documenta también en el texto), biuie (D iiii $r$ ), auie (D $\vee r$ ), gozarien (D vi v), auiemos (E i v), auie ( 2 veces, E ii $r$ ), hazie (E ii $r$ ), auie (E iii $v$ ), harie ( $\mathrm{E}$ iiii $r$ ), auriedes (F iii $r$ ), auien (G iii $r$ ) reduzien (G viii $r$ ), solie ( $\mathrm{H}$ iii $v$ ) auries ( $\mathrm{H}$ iiii $v$ ), atajaries ( $\mathrm{H}$ iiii $v$ ). La frecuencia con que se documentan los tiempos de haber, no es relevante, dada la altísima incidencia de este verbo a lo largo de toda la obra.

Algunas particularidades en cuanto a la presencia y distribución del alomorfo -ie-. Atajaries (único caso en posición de rima) y auries se encuentran en versos sucesivos. Pero asimismo auie y auia forman parte de una sola estrofa. En una misma plana figuran 2 testimonios de auie y otro de hazie, rodeados por 5 imperfectos en -ia-. Por el contrario, auriedes aparece aislado en otra que recoge 9 incidencias de variados testimonios de -ia-. De estas observaciones se desprende que la utilización de una $u$ otra variante no responde a ninguna norma ni propósito, antes bien prueba la espontaneidad de su uso, si bien claramente minoritario para -ie-.

La Arcadia contiene bastantes casos de dobletes: agora $\sim$ ahora, guirnalda $\sim$ guirnarda, teniendo $\sim$ tiniendo, etc. Creo que entre estos pares, indicio de una situación idiomática vacilante todavía, debe ser incluida la doble forma del imperfecto y del condicional. 


\section{CONCLUSIÓN}

42. Con apreciables opiniones discrepantes sobre la perduración de los imperfectos y condicionales con desinencia en -ie-, la doctrina generalizada entre los tratadistas actuales enseña que no llegan prácticamente al siglo XVI. Las opiniones más favorables a su supervivencia acusan, con mención imprecisa, la presencia, a comienzos de dicho siglo, de los últimos testimonios, po$\cos$ y aislados, de naturaleza regional y vulgar. Su fuente de información deben de ser noticias antiguas, desde mediados del mismo siglo hasta bien entrado el siguiente, que dan cuenta de su existencia, para censurarla, en Castilla la Vieja y algunas regiones de la España meridional. Hace quince años, las citadas formas verbales fueron advertidas en el habla rural toledana.

Mi objetivo era documentar la realidad de las noticias antiguas. Desde las postrimerías del siglo XV hasta los años iniciales del siglo XVII, la revisión de una nutrida nómina de textos literarios ha tenido como finalidad atestiguar la presencia en ellos de los mencionados alomorfos. El resultado ha sido positivo en varios autores y obras de mediano relieve, pero también en otros de superior consideración, como Santa Teresa, Valdés (presuntamente, en un solo manuscrito del Diálogo de la lengua), Delicado y una primera edición, poco ha descubierta, del Lazarillo.

Puesto que los datos inicialmente obtenidos apuntaban hacia Toledo como zona donde el fenómeno parecía denotar máxima vitalidad (si no toledanos, alguna vinculación con Toledo puede encontrarse o conjeturarse en los nombres recién citados), he dedicado una extensa y particular atención a tres autores toledanos, de los cuales he revisado todas sus obras: Alejo Venegas, Sebastián de Horozco y Garcilaso de la Vega. Añádase a ellos la traducción de la Arcadia, de Sannazaro. De este modo conseguía un amplísimo y variado corpus literario ${ }^{55}$, en prosa y en verso, impreso y manuscrito, con registros cultos y populares, que muestra la arraigada presencia en Toledo de las formas con -ie-. En Venegas sobreviven hasta la segunda mitad del siglo XVI y conjeturo que su actividad docente en Madrid le obligó a la rectificación; en Horozco se prolongan aún varios decenios.

Si bien cada vez más reducido en los propios autores examinados, ese arraigo en textos impresos del arcaísmo morfológico autoriza a suponer que su vitalidad se mantuviese en la lengua oral toledana (a ella pueden res-

\footnotetext{
${ }^{55}$ No me ha sido posible disponer de textos de otra naturaleza, cuyo examen resultaría de máximo interés. Será preciso proceder con gran cuidado en la consulta de fuentes documentales, pues de no haberse procedido con todo rigor y debido conocimiento en su trascripción, parece fácil que enmienden intencionadamente -ie- por -ia-. La documentación privada procedente de personas con escasa cultura es la que más se presta a descubrir la probable continuidad de las formas antiguas, hoy marginadas.
} 
ponder los toscos villancicos de 1603), luego reducido al registro vulgar. De su persistencia en ámbitos rurales hasta el presente, el testimonio parece imponerse sobre la conjetura.

Aunque la existencia de -ié- queda ampliamente testimoniada, su presencia en todos y cada uno de los textos resulta minoritaria respecto de -ía-. Son muy escasas, por el contrario, las ocurrencias de -ie-, -iá-, pero no han de extrañar: aparte de sus antecedentes históricos, tales variantes, en un sistema en que predomina la alternancia $-i a-\sim-i e ́-$, pueden entenderse como solución de compromiso entre las dos desinencias más frecuentes.

El particular punto examinado se alza en detrimento de la concepción de modelo idiomático - yo mismo he aportado numerosos testimonios al respecto- que de modo tradicional se atribuye al habla toledana desde mediados del siglo XVI. Pero de la escasa o marginal vitalidad posterior de aquél constituye precisamente un indicio dicho reconocimiento normativo ${ }^{56}$.

$P . S$. Examinada en el lugar oportuno ( $§ 41)$ la traducción española de la Arcadia (Toledo, 1547, por Juan de Ayala, en la reproducción facsimilar de 1966), hasta después de corregir pruebas no me ha sido materialmente posible consultar las ediciones posteriores a la primera. Según mis informaciones bibliográficas, no aparecen nuevas traducciones sino hace pocos decenios. La versión toledana conoció varias ediciones durante el siglo XVI y luego dejó de publicarse. Ahora he podido cotejarlas todas en la Biblioteca Nacional de Madrid. Doy cuenta individual de cada una de ellas, para consignar los datos que afectan a la morfología de imperfecto y condicional.

Toledo, 1549, también por Juan de Ayala, «reimpresa a plana y renglón» (según C. Pérez Pastor, La imprenta en Toledo. Madrid, 1887, pág. 97), enmienda, sin embargo, una aparición de auie en auia, así como igualmente auiemos en auiamos. La rotunda preferencia del texto inicial por $i a-$, según quedó antes mostrado, hace comprensible, aunque parco, el cambio introducido.

Estella, 1562, por Luis Gutiérrez, sustituye 6 casos de auie(n) por hauia(n), auiemos por hauiamos, hazie por hazia, harie por harian, reduzien por reduzian, solie por solia. La corrección fue, en efecto, notable, pero no tan dilatada como se hubiera presumido, en principio y asimismo al observar que ha adoptado una corrección sistemática para el verbo /haber/, como es la presencia de $h$ - inicial en todas sus ocurrencias. Pues si bien se normalizan 11 formas verbales, escapan a la sustitución 8 casos, es decir, mantienen $-i e$ -

\footnotetext{
${ }^{56}$ De manera análoga a como sobre el prestigio idiomático de Valladolid se proyectan las conocidas anomalías léxico-sintácticas de determinados verbos (caer, dejar, quedar).
} 
Salamanca, 1573, por Simón de Portonarii, enmienda únicamente auie por auia, reduzien por reduzian. Aquí, lejos de Toledo, y, en particular, a la vista del proceso experimentado por la edición de Estella, sorprende la fidelidad a las formas peculiares de la edición princeps.

Salamanca, 1578, por el mismo impresor, «diligentemente correcta y emendada», coincide con la edición anterior en los cambios efectuados.

Salvo en un pasaje de la versión original toledana en que, por encontrarse la correspondiente forma con -ié- en posición de rima: atajariés / ves, se hubiera renunciado al cambio, ante la necesidad de introducir alguna otra modificación, la regularización no ofrecía ninguna dificultad. Por eso, según vengo comentando, extraña que no se hubiera impuesto de modo general.

Hablar de respeto al texto inicial no constituye una explicación, a mi entender, sino que proporciona simple noticia de la situación. Me inclino, por consiguiente, a suponer que existía una mayor tolerancia de la que suele suponerse hacia el alomorfo -ie-, actitud que enlazo con las afirmaciones de Correas $(\S 4)$. En consecuencia, también cabe suponer una más amplia difusión, durante el citado siglo XVI, de las formas minoritarias, quizá inadvertidas por no consultarse ediciones originales, sino modernas, en cuya preparación han podido interpretarse como errores materiales y, por tanto, quedar eliminadas (recuérdense los casos antes citados, $\S \S 8-12$, de Santa Teresa y otros escritores de su tiempo). 